\title{
Sinusoidal Pulse Width Modulation for a PhotoVoltaic Based Single Stage Inverter
}

\section{Bolisetti Kavya Santhoshi}

Godavari Institute of Engineering and Technology (A)

Kuppusamy Mohanasundaram

KPR Institute of Engineering and Technology

\section{Vishnu Kumar Kaliappan}

KPR Institute of Engineering and Technology

Ravishankar Sathyamurthy ( $\nabla$ raviannauniv23@gmail.com )

KPR Institute of Engineering and Technology https://orcid.org/0000-0002-2881-3455

\section{Research Article}

Keywords: harmonics, inverter, single-stage conversion, photovoltaic, pulse width modulation (PWM), quasi-impedance source inverter (Q-ZSI).

Posted Date: May 13th, 2021

DOI: https://doi.org/10.21203/rs.3.rs-446191/v1

License: (c) (1) This work is licensed under a Creative Commons Attribution 4.0 International License. Read Full License

Version of Record: A version of this preprint was published at Environmental Science and Pollution Research on January 7th, 2022. See the published version at https://doi.org/10.1007/s11356-021-184221. 


\title{
Sinusoidal Pulse Width Modulation for a PhotoVoltaic based Single stage
} Inverter

\author{
Bolisetti Kavya Santhoshi ${ }^{a}$, Kuppusamy Mohanasundaram ${ }^{\mathrm{b}}$, Vishnu Kumar Kaliappan ${ }^{\mathrm{c}}$, Ravishankar \\ Sathyamurthy ${ }^{\mathrm{d}^{*}}$ \\ ${ }^{\text {a }}$ Department of Electrical and Electronics Engineering, Godavari Institute of Engineering and \\ Technology (A), Andhra Pradesh, India \\ ${ }^{\mathrm{b}}$ Department of Electrical and Electronics Engineering, KPR Institute of Engineering and Technology, \\ Coimbatore, Tamil Nadu, India \\ ${ }^{c}$ Department of Computer Science Engineering, KPR Institute of Engineering and Technology, \\ Coimbatore, Tamil Nadu, India \\ ${ }^{\mathrm{d}}$ Department of Mechanical Engineering, KPR Institute of Engineeirng and Technology, Coimbatore, \\ Tamil Nadu, India \\ *Corresponding author
}

Dr. Ravishankar Sathyamurthy, Department of Mechanical Engineering, KPR Institute of Engineeirng and Technology, Coimbatore, Tamil Nadu, India, raviannauniv23@gmail.com

\begin{abstract}
The work proposed in this paper focuses on providing an effective solution to shortage of power in rural areas with an effective technique implemented in an economically feasible way. The traditional Inverters used for either residential or commercial purposes consume electrical energy from the grid to fulfill the charging and discharging of the battery, which may lead to overloading. The shortcomings of the traditional inverters such as Non-Renewable nature of power sources, increased cost of manufacturing, and multi-stage conversion complexity, are considered by the researchers for improvement. As a result, an attempt has been made to provide a cost effective renewable energy system with single stage topology for AC power applications. Single stage power conversion with allowed shoot through state is used here to avoid additional components and reduce the switching losses. Unlike the traditional inverters, the Quasi Impedance Source Inverter that is brought forward can be utilized as a Standalone system or a capable backup at the time of power outages. Sinusoidal pulse width modulation (SPWM) is applied to attain reduced harmonics which are measured by observing the harmonic pattern in Total Harmonic Distortion (THD) curve. The lab results obtained through MATLAB simulation confirm the noteworthy diminution of THD level in the proposed system compared to the reported one. Usage of Photovoltaic (PV) Panel to tap energy with reduced stochastic fluctuations due to high filtering capacity of the proposed circuit, eliminating the need of additional filters, is the uniqueness of this technique.
\end{abstract}


Keywords: harmonics; inverter; single-stage conversion; photovoltaic; pulse width modulation (PWM);

34 quasi-impedance source inverter (Q-ZSI).

\section{Abbreviations used:}

36 THD - Total Harmonic Distortion

37 PWM - Pulse width modulation

38 SPWM - Sinusoidal Pulse Width Modulation

39 SHEPWM - Specific Harmonic Elimination Pulse Width Modulation

40 PV - Photovoltaic

41 ZSI - Impedance source inverter

42 QZSI - Quasi impedance source inverter

43 MPPT - Maximum Power point Tracking

44 PQ - Power Quality

\section{I. INTRODUCTION}

46 Solar power is mostly preferred due to ease in application compared to other forms of green energy. Also,

47 solar power is readily available free of cost. Utilizing PV is the latest trend in research due to green

48 energy. The proposed work is extracted from the research works related to Grid connected PV systems,

49 Impedance Source Inverters (ZSIs), PWM techniques and Quasi-Impedance Source Inverter (QZSIs)

50 (Kavya Santhoshi et al. (2019)). The Impedance-source inverter incorporates an LC network (or circuit)

51 that overcomes the disadvantages of the reported inverters. From this paper, one can infer that the concept

52 of using a Z-source can be extended to all forms of power conversion. The objective of the presented

53 work is set from the literature review mentioned in the section that follows.

54 In 2003, the idea of $\mathrm{Z}$ source inverters was introduced and the altered control methods were studied (Peng 55 et al. (2019); Anderson and Peng (2005)). In 2011, research area focused more on Renewable form of 56 energy. It is proved that when power obtained from PV panels is lesser than that of the grid, the battery is 57 discharged and vice versa ( $\mathrm{Li}$ et al. (2011); Cintron-Rivera (2011); Zhang et al. (2012)). In order to track 58 maximum power, novel MPPT algorithms were proposed (Riffonneau et al. (2010)). In order to balance 59 the fluctuations in solar power, energy can be stored in a storage device such as battery, to supply the load 60 demand during critical situations (Vinnikov and Roasto (2010); Barrade et al. (2012)). Later in 2012, the 61 usage of super capacitors integrating MPPT was depicted (Makarov et al. (2011)). The sizing of batteries 62 for different energy forms was also discussed in the same year (Santhoshi et al. (2014)). In 2014, usage of 
SHEPWM was explained and verified with the results. It proved to have lesser harmonics compared to previous topologies (Kadri et al. (2010)). Later part of the same year, a method to inculcate constant peak voltage that is present at the dc link was brought to the limelight. In 2015, for various load conditions, an analysis of the impedance source inverter was done (Kavya Santhoshi and Sudharsan (2015)). In case of bidirectional DC-DC converter, batteries are employed for energy storage and management of them yields to a system which is costly, less efficient and complex (Liu et al. (2013)). Thus, the QZSI with more advantages can be used instead of the previous topologies. In the proposed work, sinusoidal pulse width modulation is applied for controlling the switches of the inverter switches to mitigate harmonics to a 71 greater extent.

\section{REPORTED SYSTEM AND ITS DEMERITS}

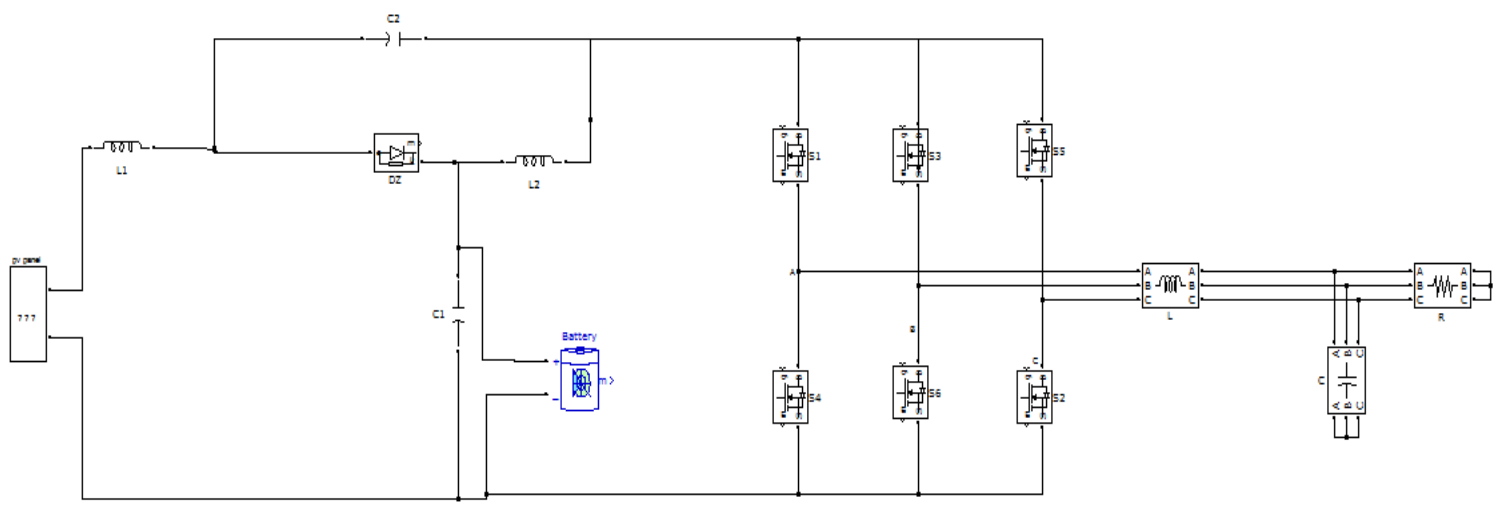

73

74

75

76

77

78

79

80

81

82

Fig. 1: Reported system - Circuit diagram in MATLAB Simulink

Fig. 1, gives the reported system's block diagram drawn using MATLAB simulation tool. It has two power sources that is both the Photovoltaic panels as well as the battery act as power sources. The load acts as he power consumer. While controlling power flows from two sources of power, the third involuntarily matches due to the equation (1).

$P_{\text {in }}-P_{\text {out }}+P_{b a t}=0$

Where, $\mathrm{P}_{\text {in }}$ is the power at the input side due to $\mathrm{PV}$, Pout is the power at the output due to inverter and $\mathrm{P}_{\text {bat }}$ is the power due to battery. $\mathrm{P}_{\text {in }}$ is a one-way power flow and $\mathrm{P}_{\text {bat }}$ is a two-way power flow. It has two modes: shoot-through mode which is undesirable in conventional inverters and the non-shoot-through mode. When the mode is shoot-through, reverse biased diode gets turned off. While operating in nonshoot through mode, the quasi-impedance source inverter presumes one state out of the available active states (six in number) and zero states (two in numbers). 


\section{PROPOSED WORK AND ITS MERITS}

The proposed work uses a QZSI compared to the traditional inverter. There are certain benefits of using this topology. The inductor and capacitor elements present in the quasi z source network behave as storage elements. When solar power is available, these elements get charged by solar voltage and later when the solar source is unavailable, these elements discharge the voltage. Hence high voltage at the output of this network can be obtained since voltage from battery and the quasi z source network elements get summed to produce higher voltage. The current in the circuit remains constant. Boost feature is one of the important features of a quasi impedance source network.

Fig. 2, gives the proposed work's block diagram which comprises of PV panel and battery, Quasi $\mathrm{Z}$ source network, three phase inverter and induction motor Input voltage is DC voltage obtained from a PV panel. Energy storage is provided such that during the absence of sunlight the battery supplies the input to the Quasi-Impedance source network.

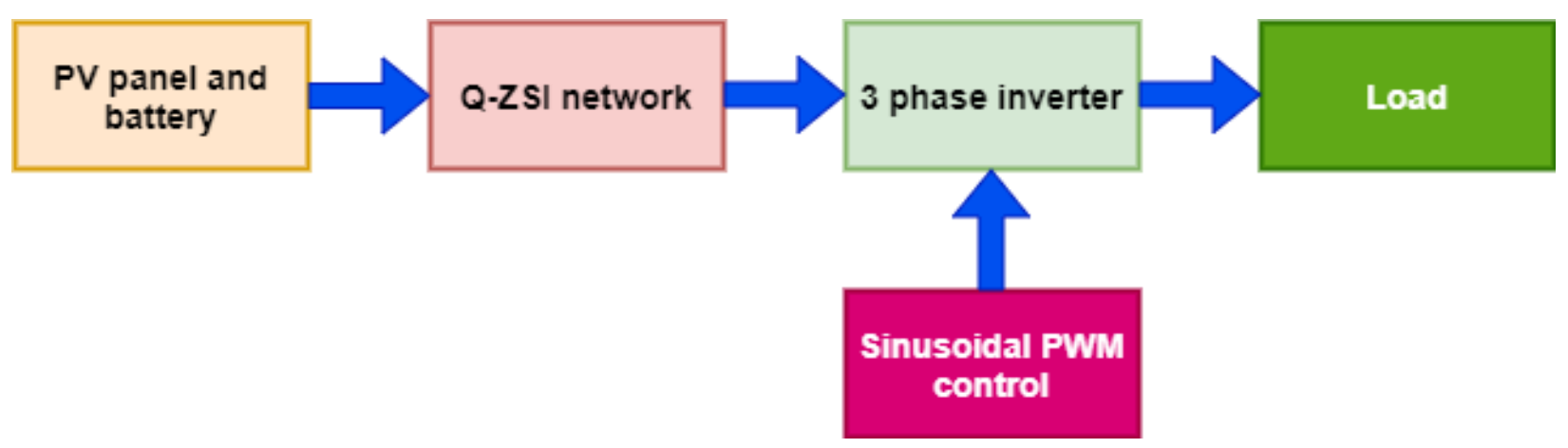

Fig. 2: Proposed quasi impedance source inverter - Block diagram

\section{THE CONTROL TECHNIQUE}

Fig. 3 shows the proposed work's circuit diagram drawn using MATLAB simulation tool. There exists a DC source from PV panel, two capacitors and two inductors along with a unidirectional switch (diode) forming the Q-ZSI network and the three phase inverter. QZSI circuit is unique when compared to other traditional ZSIs because of the occurrence of inductor-capacitor setup between PV and inverter (Santhoshi et al. (2016)). Any damage during shoot through state is prevented due to the presence of this structure. A QZSI is operated in two modes: shoot through and non-shoot through. Voltage boosting occurs during shoot through state (Liu et al. (2014); Abu-Rub et al. (2012); Liu et al. (2012); Sun et al. (2013)).

The reference signal is a sinusoidal wave and the carrier signal is triangular. The gate signal is generated by comparing these two signals. The pulse width is varied in accordance with the magnitude of the reference signal calculated at the center of the pulse. The modulation index can determine the output voltage. Hence the harmonics are reduced in the output voltage. A cost effective and energy efficient 
113 system with reduced components due to absence of two stage conversion can be achieved. The

114 modulation index is given by equation (2).

$115 \quad m=\frac{V_{m}}{V_{c}}$

116 Where, $V_{m}$ is the voltage of the modulating signal and $V_{c}$ is the voltage of the carrier signal.

$117 V_{m}=\frac{\left(V_{\text {max }}-V_{\text {min }}\right)}{2}$

118

$V_{c}=\frac{\left(V_{\max }+V_{\min }\right)}{2}$

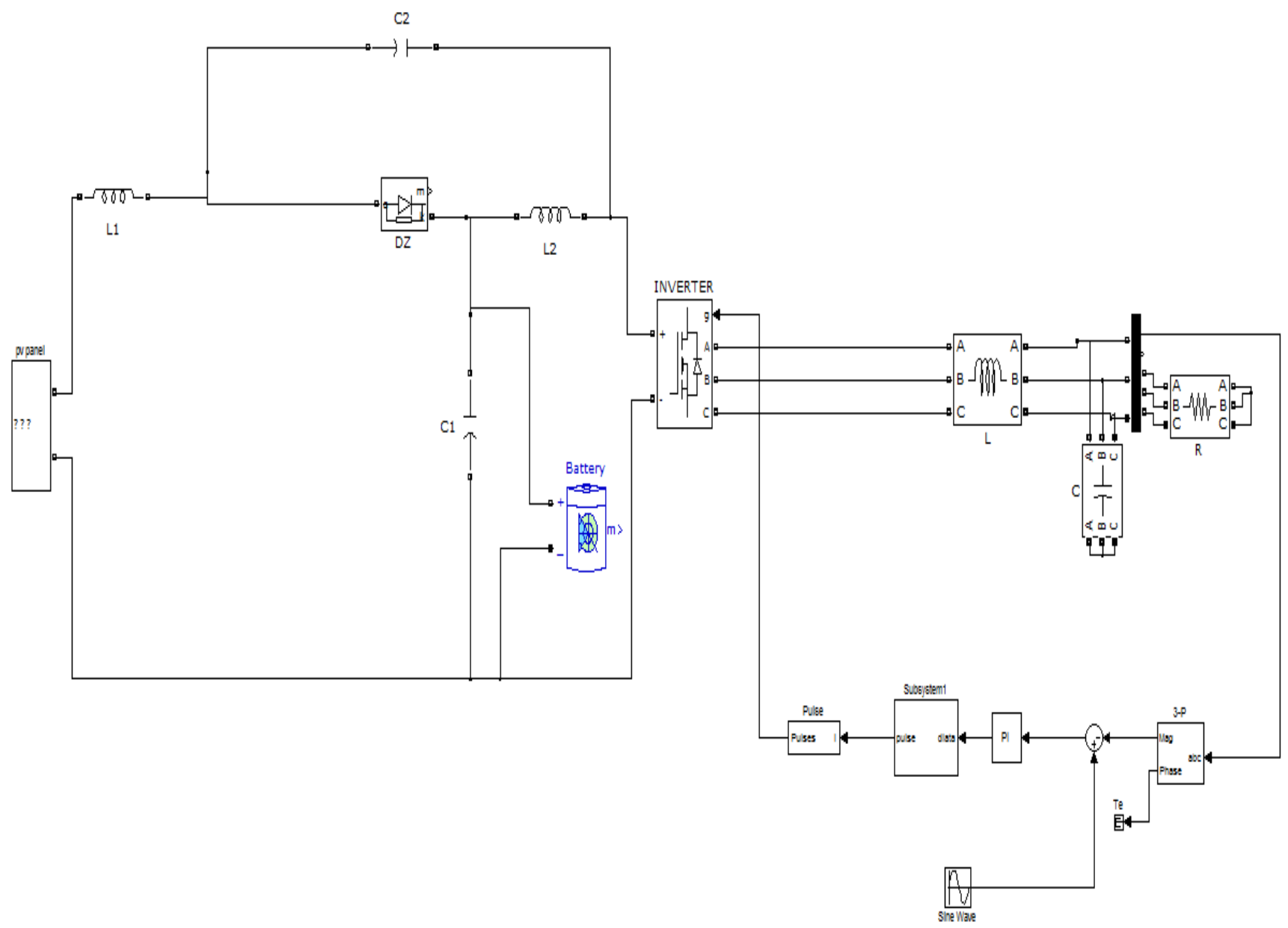


123 Q-ZSI based sinusoidal pulse width modulation techniques, which result and discussion can be briefly 124 described in the following section.

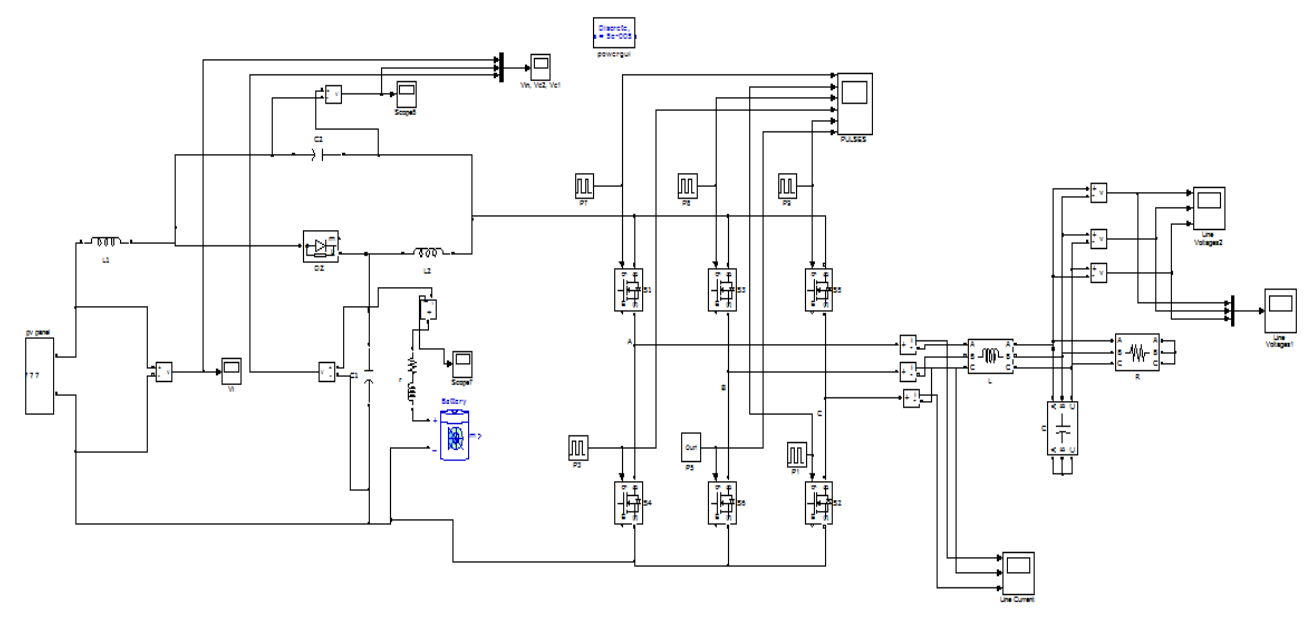

125

126
Fig. 4: Simulink model of the reported work with $\mathbf{R}$ load

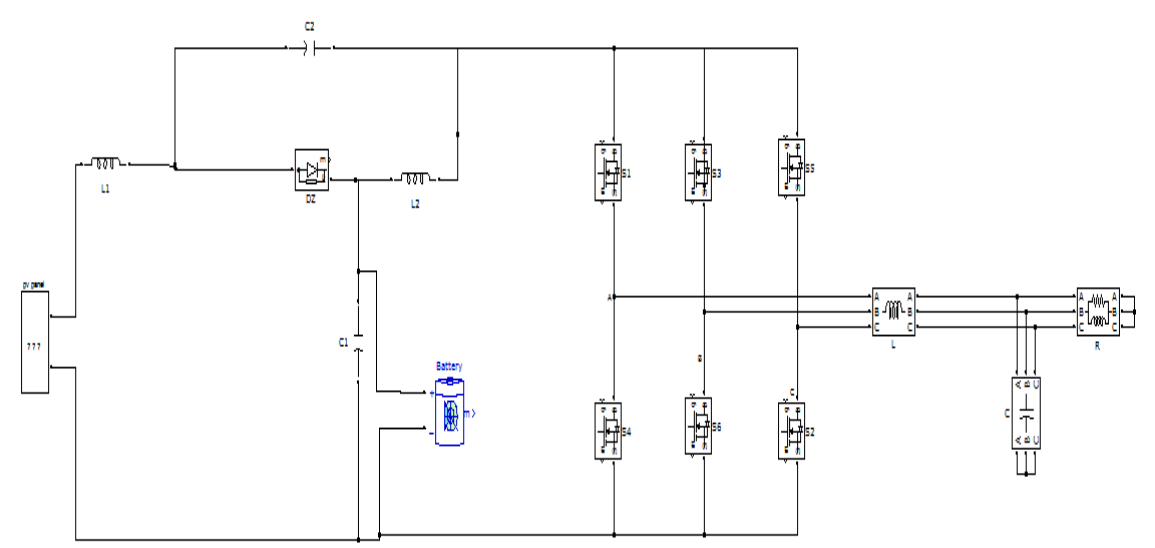

127

128

129

130

131

132

133

134
Fig. 5: Simulink model of the reported work with RL load

\section{RESULTS \& DISCUSSION}

The presented system has been simulated with input PV voltage of $52 \mathrm{~V}$. The simulation has been carried out using $\mathrm{R}$ and L loads and further research on the same using other loads is being done. The outcome of the simulation has proven to reduce THD to $1.9 \%$ compared to the reported system that yields a THD of $12.73 \%$ under R load condition. FOR RL load condition, the results show that the THD of line current reduces from a level of $14.01 \%$ to $3.81 \%$. The simulink model for the reported work and proposed 
work using R load and RL load are shown in Fig. 4, 5, 6 and 7 respectively. The parameters used for simulating the proposed model are tabulated in table 1.

Table.1: Entities used for simulation

\begin{tabular}{|l|l|}
\hline \multicolumn{1}{|c|}{ PARAMETER } & \multicolumn{1}{c|}{ VALUE } \\
\hline INPUT VOLTAGE & 52 Volts \\
\hline INPUT CURRENT & 18 Amperes \\
\hline L1 & 1 milli Henry \\
\hline L2 & 1 milli Henry \\
\hline C1 & 100 micro Farad \\
\hline C2 & 100 micro Farad \\
\hline R & 25 Ohms \\
\hline L & 100 milli Henry \\
\hline
\end{tabular}

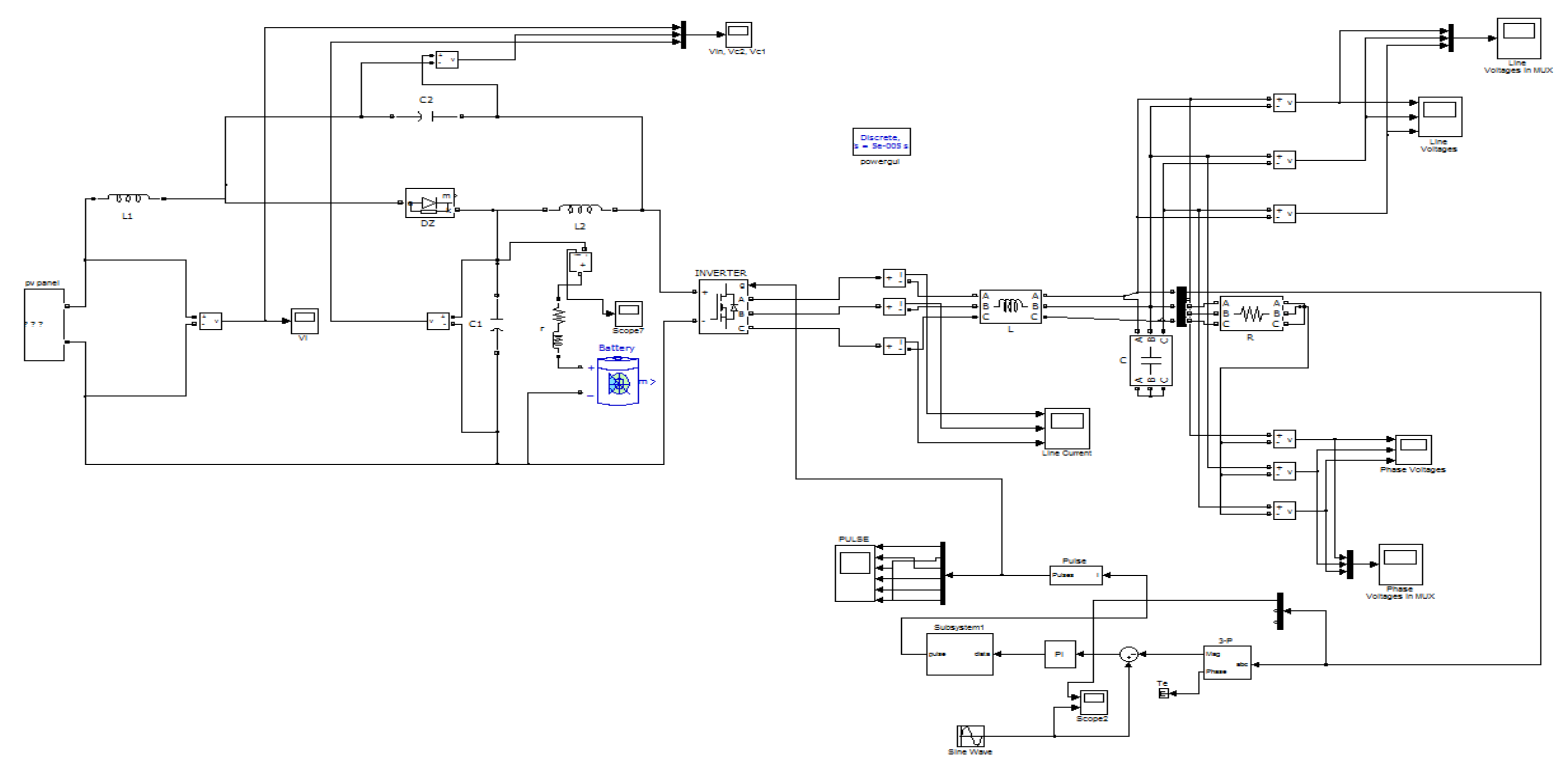

Fig. 6: Simulink model of the proposed work with R load

\section{PERFORMANCE ANALYSIS OF THE PROPOSED CONTROLLER}

The performance evaluation of the proposed system and its simulation results are analyzed for irradiance input conditions. The performance analysis of the proposed controller is tested with Q-ZSI with PV panel based sinusoidal pulse width modulation techniques in two different conditions.

* Condition 1: Analysis of R load 
The PV panel was controlled by using proposed Q-ZSI based sinusoidal pulse width modulation technique for mitigating the total harmonic distortion. While converter circuit uses predicted voltage and current control in order to have the optimal sinusoidal pulse with modulation. This system was simulated

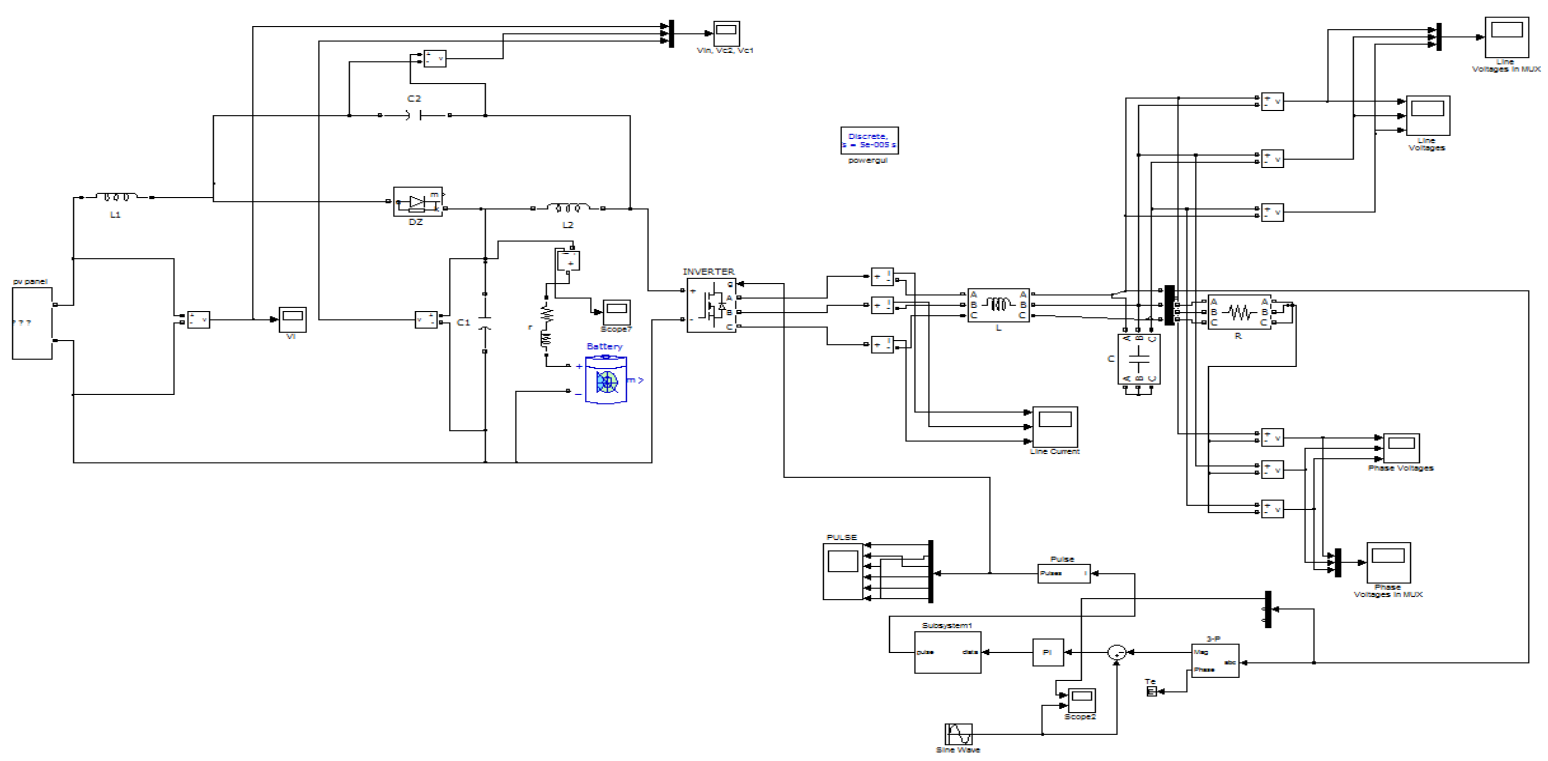

Fig. 7: Simulink model of the proposed work with RL load

\section{Analysis of case 1: $R$ load}

A seven-level Q-ZSI based SPWM technique for grid-connected PV power system is prototyped. The different PV panel voltages are performed to the Q-ZSI modules. Initially, the performance of input irradiance of the PV panel are analyzed in the ordinary condition and outlined in the Fig. 10. For analyzing the adequacy of the PV array, the harmonic distortion is resolved utilizing the proposed techniques. The modulation current, inverter voltage, load current and dc link voltage is analyzed using proposed method. Then the behavior for the optimal operation for different condition is shown. The modulation current, inverter voltage, load current, load voltage and dc link voltage is analyzed while the $\mathrm{PV}$ panel is connected with the system. In which at time $\mathrm{t}=0$ to 0.2 seconds the harmonic problems are arises and cleared using the proposed model is illustrated. The compensation performance of harmonic distortion at inverter output is analyzed using proposed techniques under irradiance. 
166

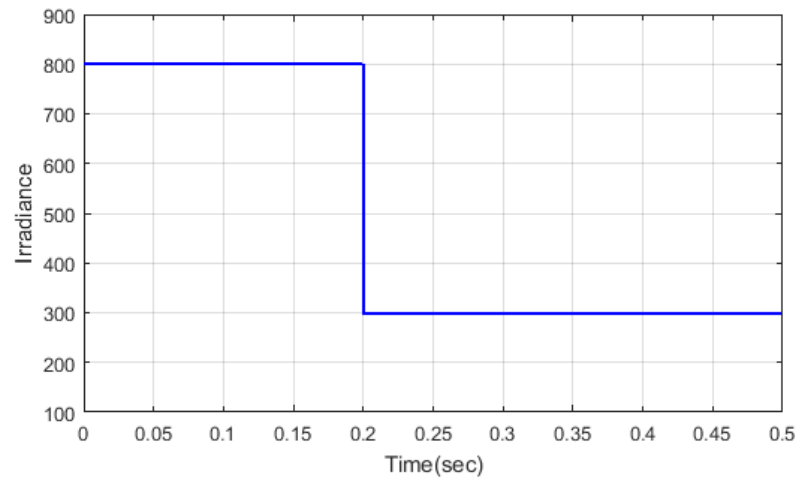

Fig. 8: Analysis of input irradiance for proposed method in $R$ load

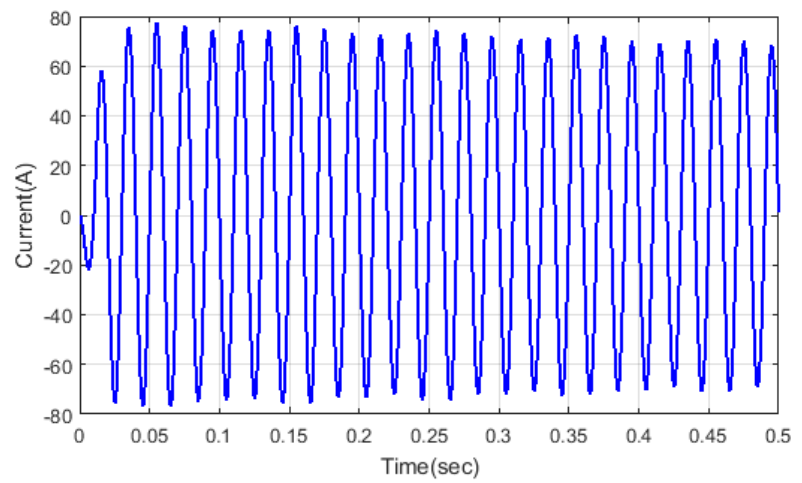

(a)

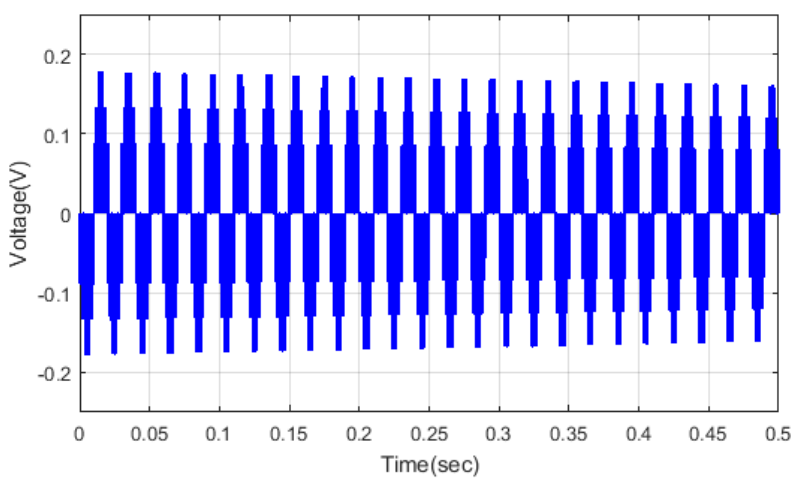

(b)

Fig. 9: Analysis of (a) modulation current and (b) inverter voltage for proposed method 


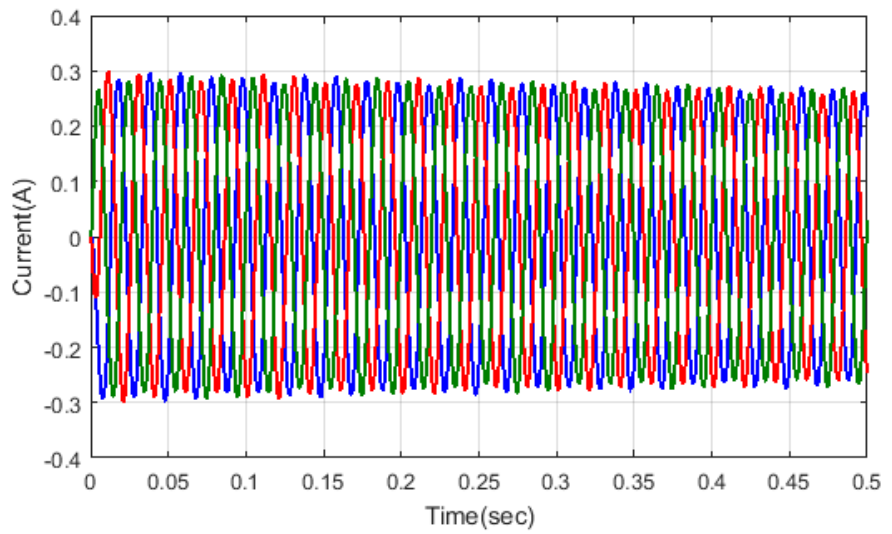

(a)

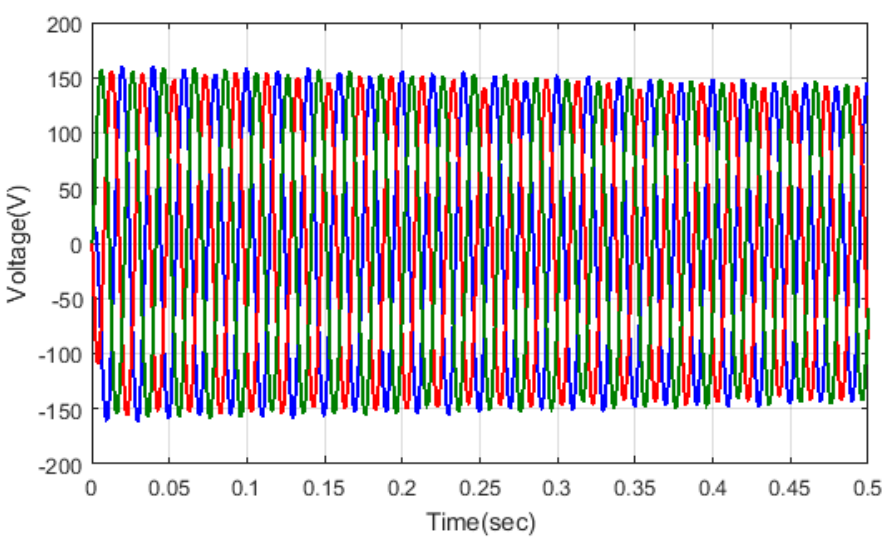

(b)

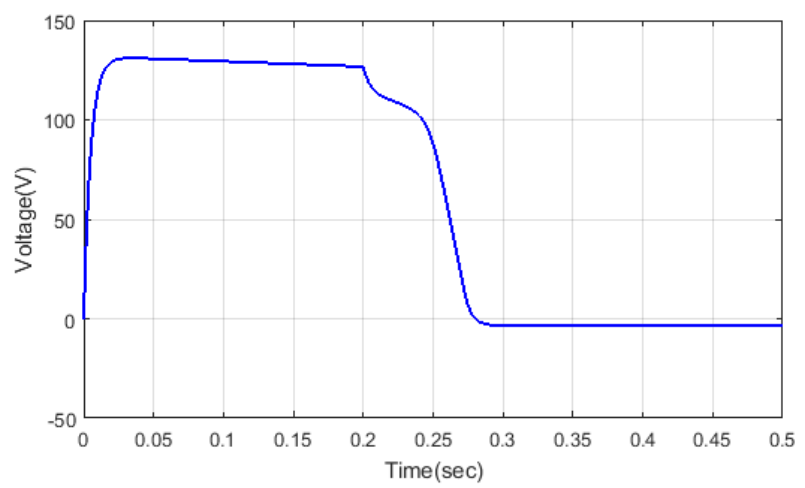

(c)

Fig. 10: Analysis of (a) load current (b) load voltage and (c) dc link voltage for proposed method

By utilizing the proposed method, the current, voltages and dc link voltage are analyzed and 181 illustrated in the figures above. From the above designs, the Power Quality (PQ) is disturbed exactly at 182 the instant, $\mathrm{T}=0.2$ seconds, defined by employing proposed method. Total harmonic distortion problems are clearing settling time at 0.29 seconds in the proposed Q-ZSI with sinusoidal pulse width modulation 
based PV panel controller. Therefore, the proposed method is easily compensating the total harmonic distortion problem when compared with the R load and RL load.

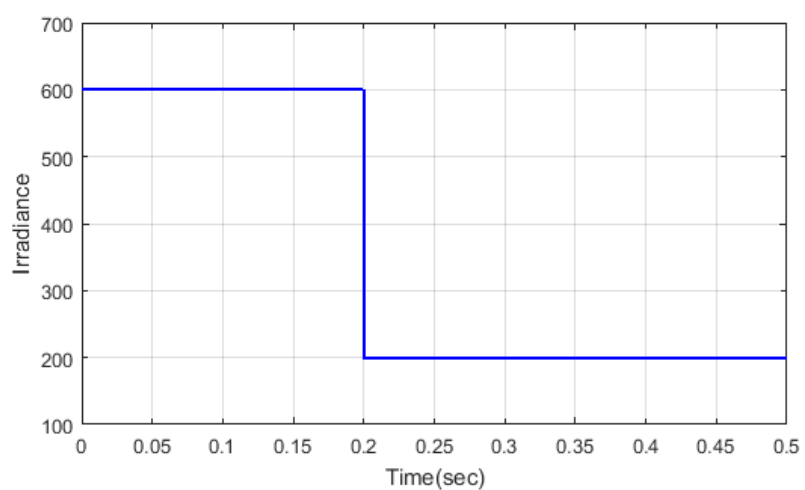

Fig. 11: Analysis of irradiance for proposed method in RL load

Here, the harmonic problem is created to analyze the performance of proposed method. By using the proposed QZSI with sinusoidal pulse width modulation based PV panel, current, inverter voltage, load current, load voltage and dc link voltage are determined. To compensate the total harmonic distortion problem, the dc link voltage performance is analyzed. Figure 11, shows that the execution of irradiance has been illustrated and Fig. 12 illustrates, performance of the current and inverter voltage has been analyzed. After that, reduced the total harmonic distortion analyzing of the load current, load voltage and dc link voltage has been illustrated in the Fig. 13. From the investigation of dc link voltage of the system is improved after injecting the compensating current and voltage. Along these lines, the total harmonics at the inverter is reduced. The general investigation of proposed strategy gives better repaying the harmonic detection successfully.

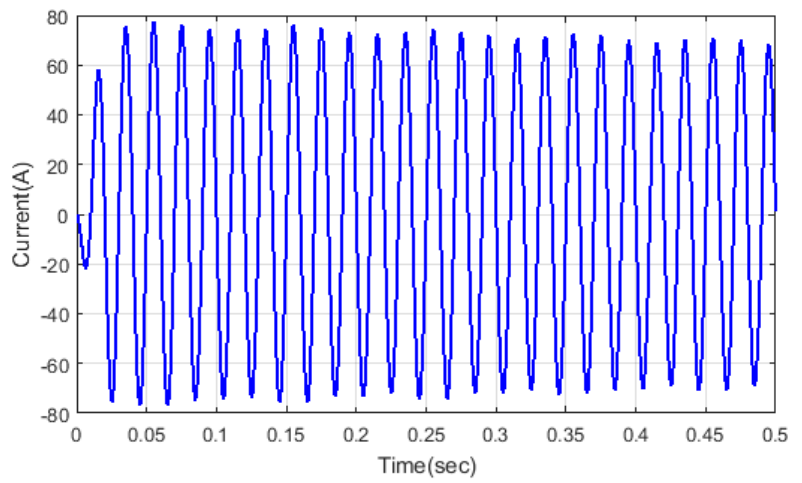




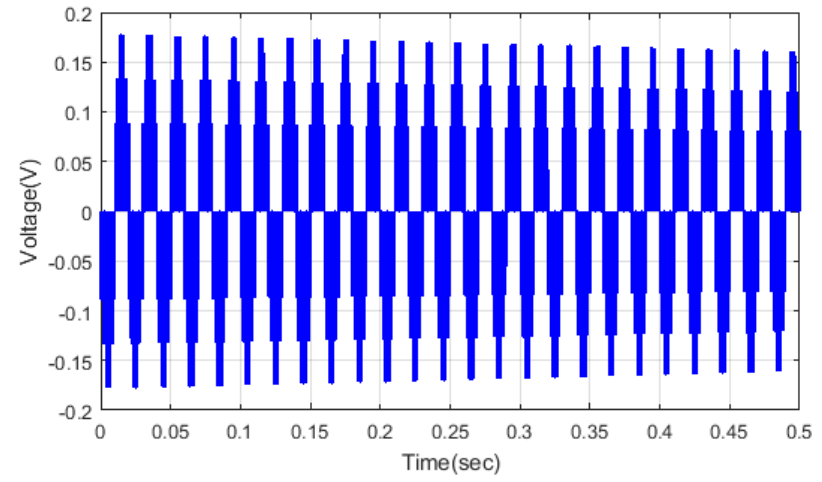

(b)

Fig. 12: Analysis of (a) current and (b) inverter voltage for proposed method

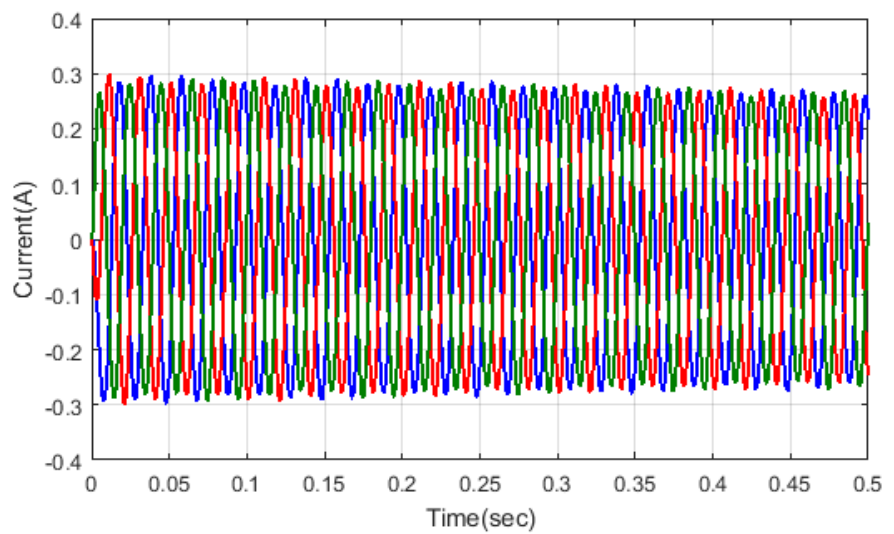

(a)

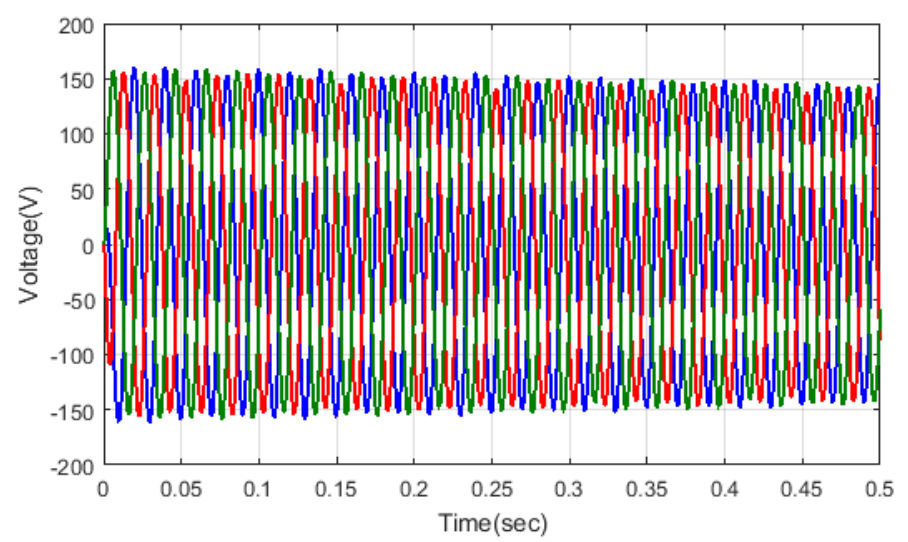

(b) 


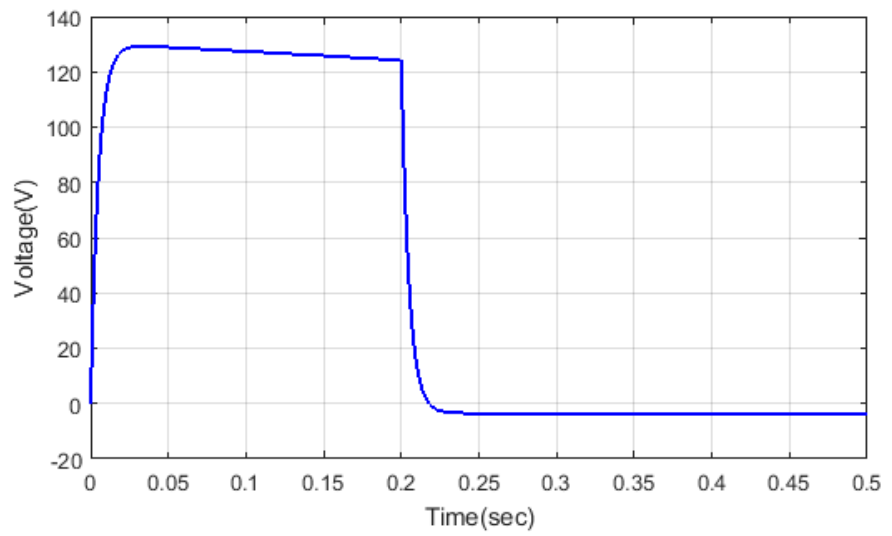

(c)

In the above Fig. 13 (a) and (b) illustrates, the analysis of the current and inverter voltage has 212 been described. Here, the proposed strategy demonstrates the strength to introduce minimal values of 213 harmonic distortion of the traditional procedure. The overall illustrations, the current and inverter voltage 214 performance of the PV panel based sinusoidal pulse width modulation technique are done in the time 215 instant $\mathrm{t}=0$ to 0.2 seconds, also the addition time instant $\mathrm{t}=0.01$ seconds uses for the PV panel. The output 216 of the proposed methodologies tracks the current and inverter voltage nearly to the reference current and 217 voltage of the proposed methodologies. In Fig. 13 (a), (b) and (c) illustrates, the performance analysis of 218 the load current, load voltage and dc link voltage has been performed. During the current take the limits at $219-0.3$ A to $0.3 \mathrm{~A}$ then the output analysis at three phae current has been performed in the Fig. 13 (a). In Fig. 22013 (b) illustrates, performance of the load voltage at takes the $150 \mathrm{~V}$ has been reached and output is the 221 three phase volage. Then the Fig. 13 (c), the analysis of the dc link voltage output has been presented. 222 Here, takes the voltage at 0 to $130 \mathrm{~V}$ it is reached the settling time at 0.23 seconds.

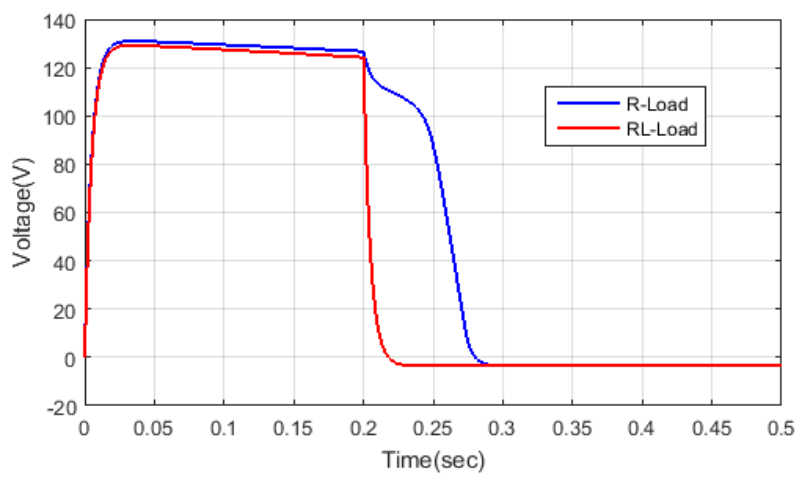


From the Fig. 14, the comparison analysis of condition 1 and condition 2 like as R load and RL load. Here, the R load and RL load performance of the dc link voltage is analyzed in various time moments at this point, the dc link voltage can be synchronized by utilizing the proposed methodologies. The dc link voltage of PV panel is roughly maintained to the reference value under all influences. The anticipated technique gives closest current and inverter voltage value to optimal value and moves constantly. But for the existing method, the current and inverter voltage values are very far from the optimal one and which cannot be feasible for offering better current and voltage. From the overall analysis, the proposed method is effectively reducing the dc voltage harmonics of the load voltage. The reference voltage extraction and the voltage regulation are accomplished while utilizing the proposed controller. Then the conditions take the time at 0 and 0.2 seconds. The $\mathrm{R}$ load is performance of the input is dc voltage and the rise time 0.002 seconds and the settling process 0.29 seconds. But the RL load is performance of take the rise time at 0.002 seconds and the settling time at 0.23 seconds. So that the comparison of the RL load is better than the R load because the settling time and total harmonic detection at inverter output are better performance. This assessment shows that the proposed methodologies is the finest method to incredulous the nonlinearity in this system with great reliability, more robust and good performance than the other approaches.

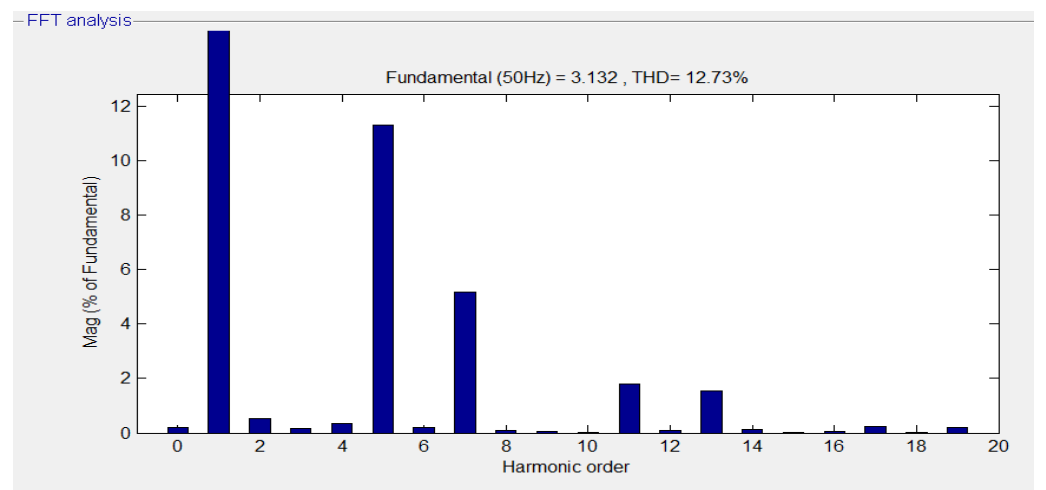

Fig. 15: THD in Line current of the reported system using $R$ load

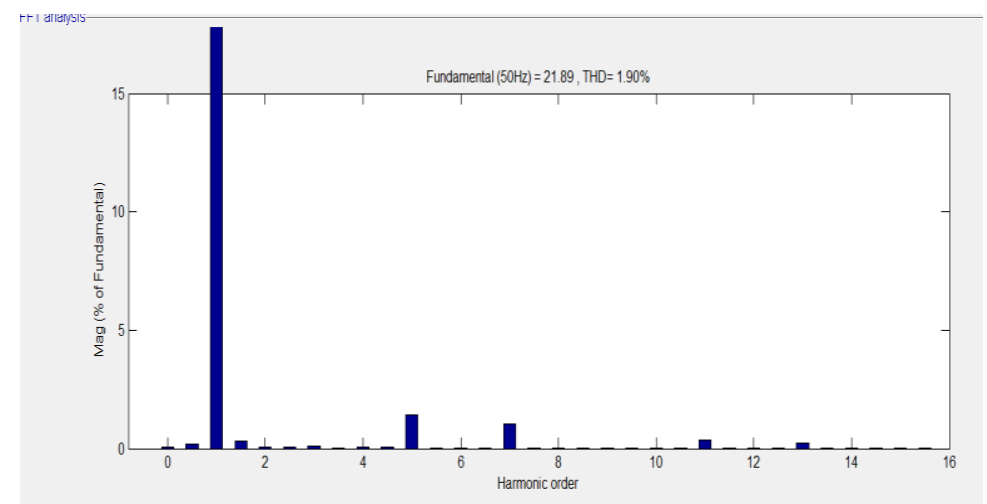




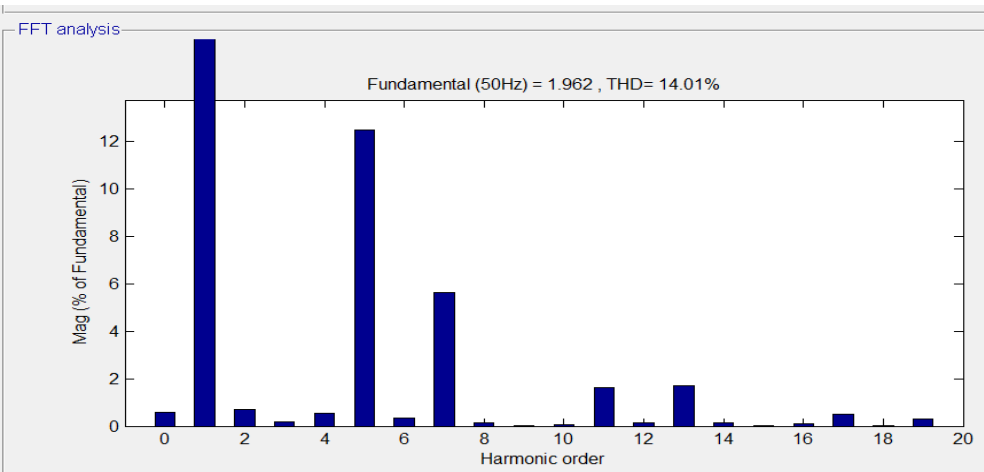

Fig. 17: THD in Line current of the reported system using RL load

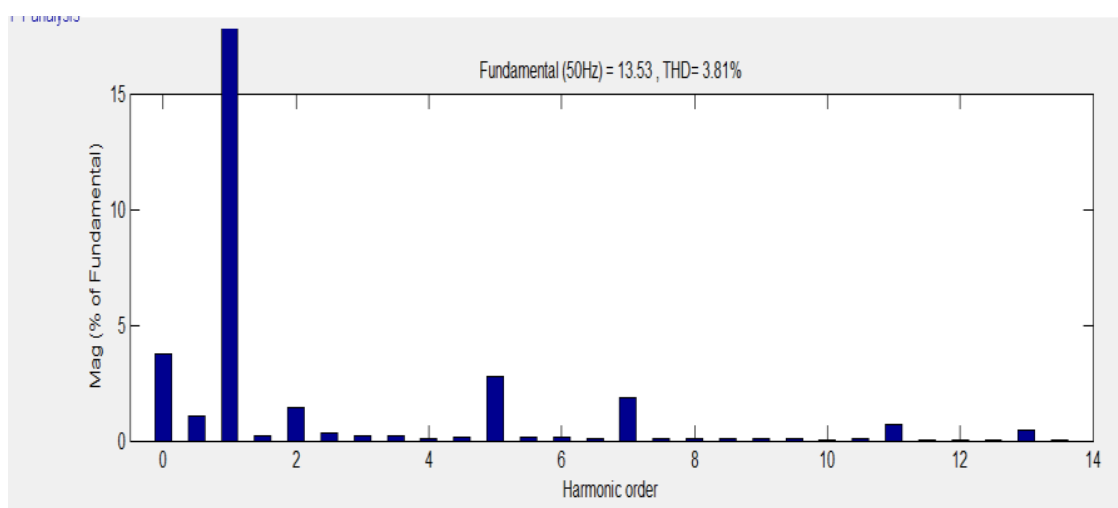

Fig. 18: THD in Line current of the proposed work with RL load

The THD levels in line current of the reported and proposed work with R and RL loads have been shown in Fig. 15, 16, 17 and 18.

\section{CONCLUSION}

This work focuses on providing an effective solution to shortage of power in rural areas. In rural areas, there is frequent outage of power. Renewable power generation systems are a good solution to overcome Global warming and preventing hazardous waste materials circulated into the atmosphere. Solar energy is preferred in places that are tropical. In this work, an improved single stage photovoltaic system with reduced harmonics and energy storage is proposed. The problem of having a less range of continuous conduction mode is overcome. The system can provide a cost effective solution for usage in rural areas. In future solar power will be a major source of power as the need for renewable energy resources has risen in the last decade.

\section{Ethical Approval}




\section{Consent to Participate}

264 Not Applicable

\section{Consent to Publish}

266 Not Applicable

\section{Authors Contributions}

268 Conceptualization, Methodology, Resources, Formal analysis, Writing - original draft preparation, review 269 and editing, Supervision and investigation were carried out by, Bolisetti Kavya Santhoshi, Kuppusamy 270 Mohanasundaram, Vishnu Kumar Kaliappan

271 Writing - original draft preparation, review and editing were carried out by Ravishankar Sathyamurthy

\section{$272 \quad$ Funding}

273 There is no funding received for the research work carried out.

\section{Competing Interests}

275 The authors declare that there is no competing interest

\section{Availability of data and materials}

277 Not Applicable

\section{REFERENCES}

279 Abu-Rub, H., Iqbal, A., Ahmed, S. M., Peng, F. Z., Li, Y., \& Baoming, G. (2012). Quasi-Z-source inverter-based photovoltaic generation system with maximum power tracking control using ANFIS. IEEE Transactions on Sustainable Energy, 4(1), 11-20. Applications Society Annual Meeting (pp. 1-7). IEEE. with on-off maximum power point tracking. IEEE Transactions on Sustainable Energy, 3(2), 283294. 
Cintron-Rivera, J. G., Li, Y., Jiang, S., \& Peng, F. Z. (2011). Quasi-Z-source inverter with energy storage for photovoltaic power generation systems. In 2011 Twenty-Sixth Annual IEEE Applied Power Electronics Conference and Exposition (APEC) (pp. 401-406). IEEE.

Kadri, R., Gaubert, J. P., \& Champenois, G. (2010). An improved maximum power point tracking for photovoltaic grid-connected inverter based on voltage-oriented control. IEEE transactions on industrial electronics, 58(1), 66-75.

Kavya Santhoshi, B., Mohana Sundaram, K., Padmanaban, S., Holm-Nielsen, J. B., \& KK, P. (2019). Critical review of PV grid-tied inverters. Energies, 12(10), 1921.

Kavya Santhoshi. B and Sudharsan. A. (2015). Performance characteristics of a Solar operated Quasi Z Source Inverter under different load conditions. Journal of chemical and pharmaceutical research.

Li, F., Ge, B., Sun, D., Bi, D., Peng, F. Z., \& Haitham, A. R. (2011). Quasi-Z source inverter with battery based PV power generation system. In 2011 International Conference on Electrical Machines and Systems (pp. 1-5). IEEE.

Liu, J., Jiang, S., Cao, D., \& Peng, F. Z. (2012). A digital current control of quasi-Z-source inverter with battery. IEEE Transactions on Industrial Informatics, 9(2), 928-937.

Liu, Y., Ge, B., Abu-Rub, H., \& Peng, F. Z. (2013). Control system design of battery-assisted quasi-Zsource inverter for grid-tie photovoltaic power generation. IEEE Transactions on Sustainable Energy, 4(4), 994-1001.

Liu, Y., Ge, B., Abu-Rub, H., \& Peng, F. Z. (2014). An effective control method for three-phase quasi-Zsource cascaded multilevel inverter based grid-tie photovoltaic power system. IEEE Transactions on Industrial Electronics, 61(12), 6794-6802.

Makarov, Y. V., Du, P., Kintner-Meyer, M. C., Jin, C., \& Illian, H. F. (2011). Sizing energy storage to accommodate high penetration of variable energy resources. IEEE Transactions on sustainable Energy, 3(1), 34-40.

Peng, F.Z., Joseph, A., Wang, J., Shen, M., Chen, L., Pan, Z., Ortiz-Rivera, E. and Huang, Y. (2005). Zsource inverter for motor drives. IEEE transactions on power electronics, 20(4), pp.857-863.

Riffonneau, Y., Bacha, S., Barruel, F., \& Ploix, S. (2011). Optimal power flow management for grid connected PV systems with batteries. IEEE Transactions on sustainable energy, 2(3), 309-320. 
Santhoshi, B. K., Divya, S., \& Kumar, M. S. (2014). Selective harmonic elimination for a PV based Quasi-Z Source Inverter for drive systems. In 2014 IEEE National Conference on Emerging Trends In New \& Renewable Energy Sources And Energy Management (NCET NRES EM) (pp. 143-147). IEEE.

Santhoshi, B. K., Sundaram, K. M., Sivasubramanian, M., \& Akila, S. (2016). A novel multiport bidirectional dual active bridge dc-dc converter for renewable power generation systems. Indian Journal of Science and Technology, 9(1), 1-4.

Sun, D., Ge, B., Bi, D., \& Peng, F. Z. (2013). Analysis and control of quasi-Z source inverter with battery for grid-connected PV system. International Journal of Electrical Power \& Energy Systems, 46, 234240.

Vinnikov, D., \& Roasto, I. (2010). Quasi-Z-source-based isolated DC/DC converters for distributed power generation. IEEE Transactions on Industrial Electronics, 58(1), 192-201.

Zhang, P., Wang, Y., Xiao, W., \& Li, W. (2012). Reliability evaluation of grid-connected photovoltaic power systems. IEEE transactions on sustainable energy, 3(3), 379-389. 
Figures

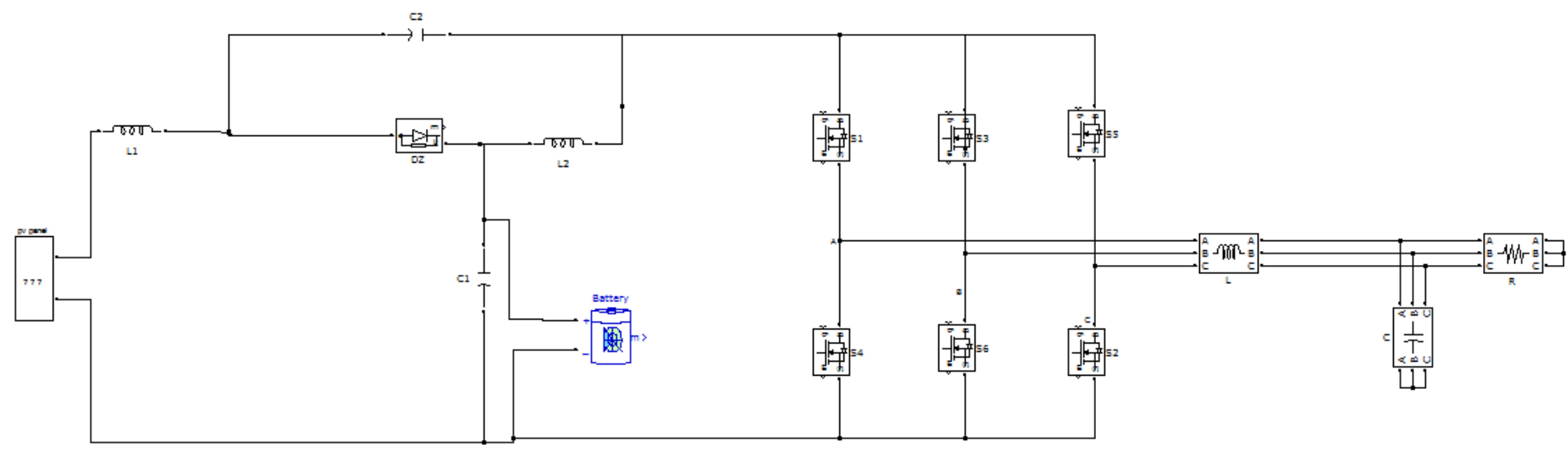

Figure 1

Reported system - Circuit diagram in MATLAB Simulink

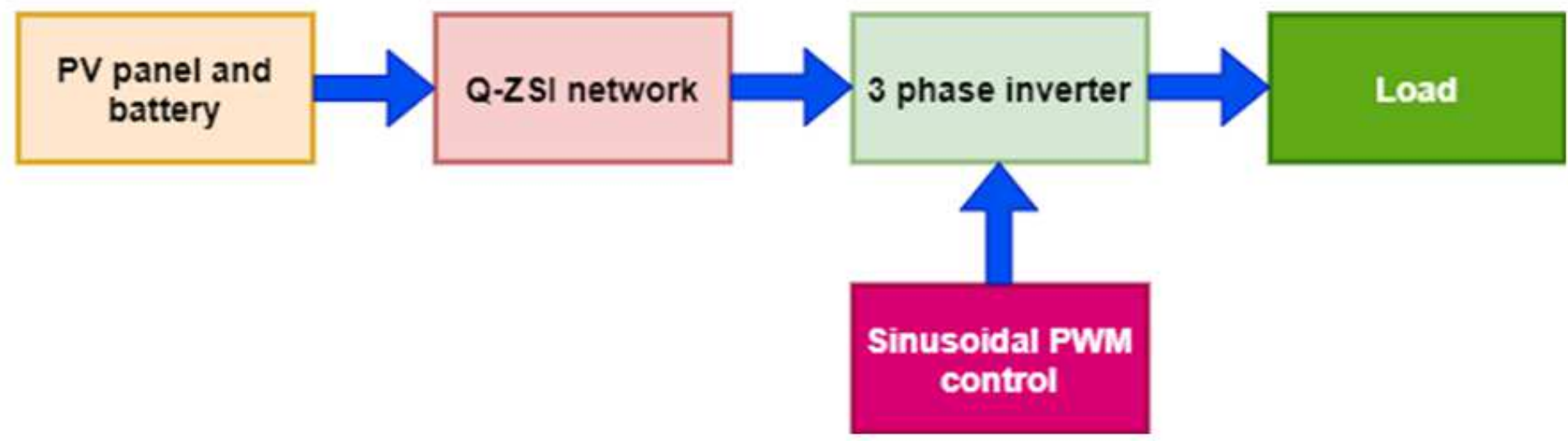

Figure 2

Proposed quasi impedance source inverter - Block diagram 


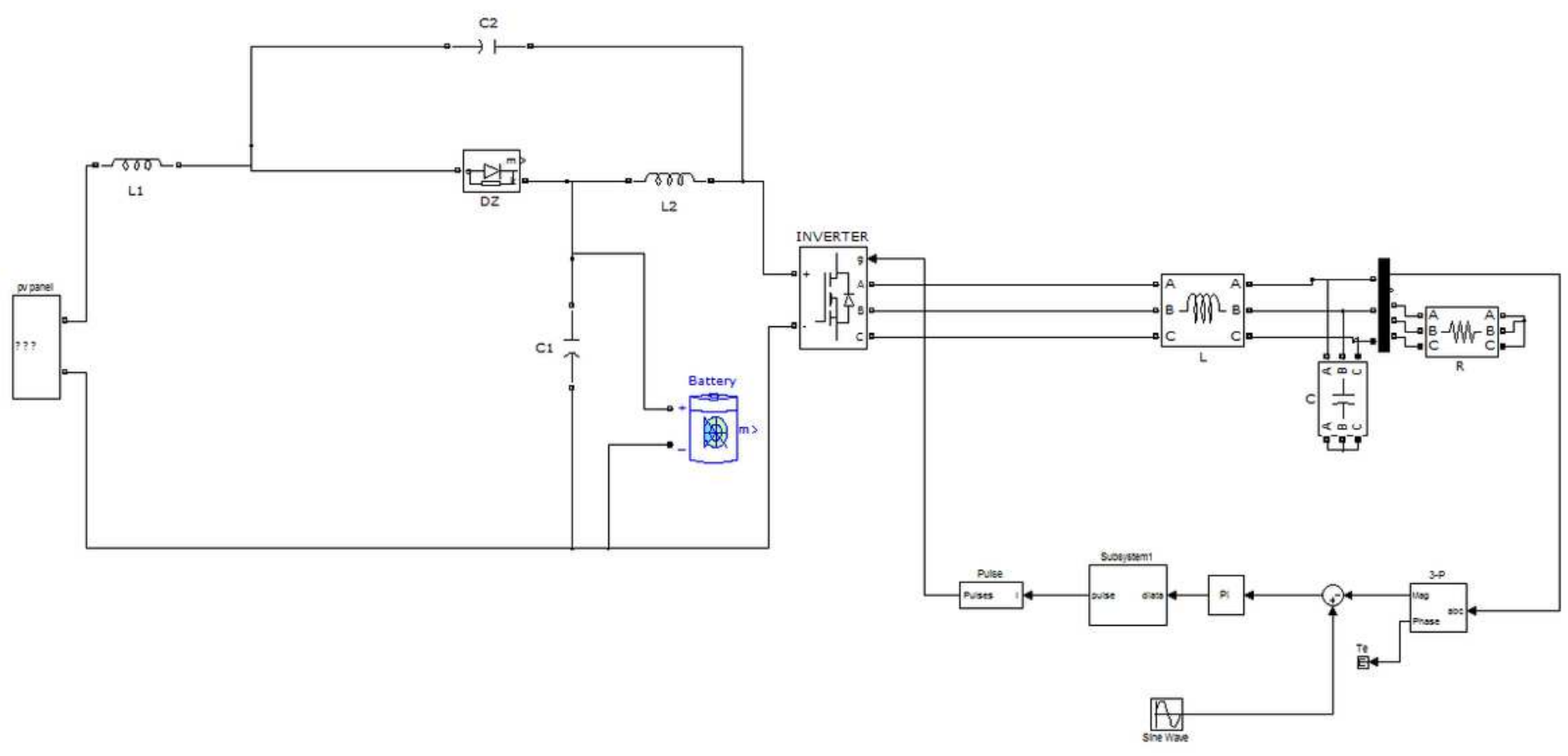

Figure 3

Proposed quasi impedance source inverter with SPWM - Circuit diagram in MATLAB Simulink

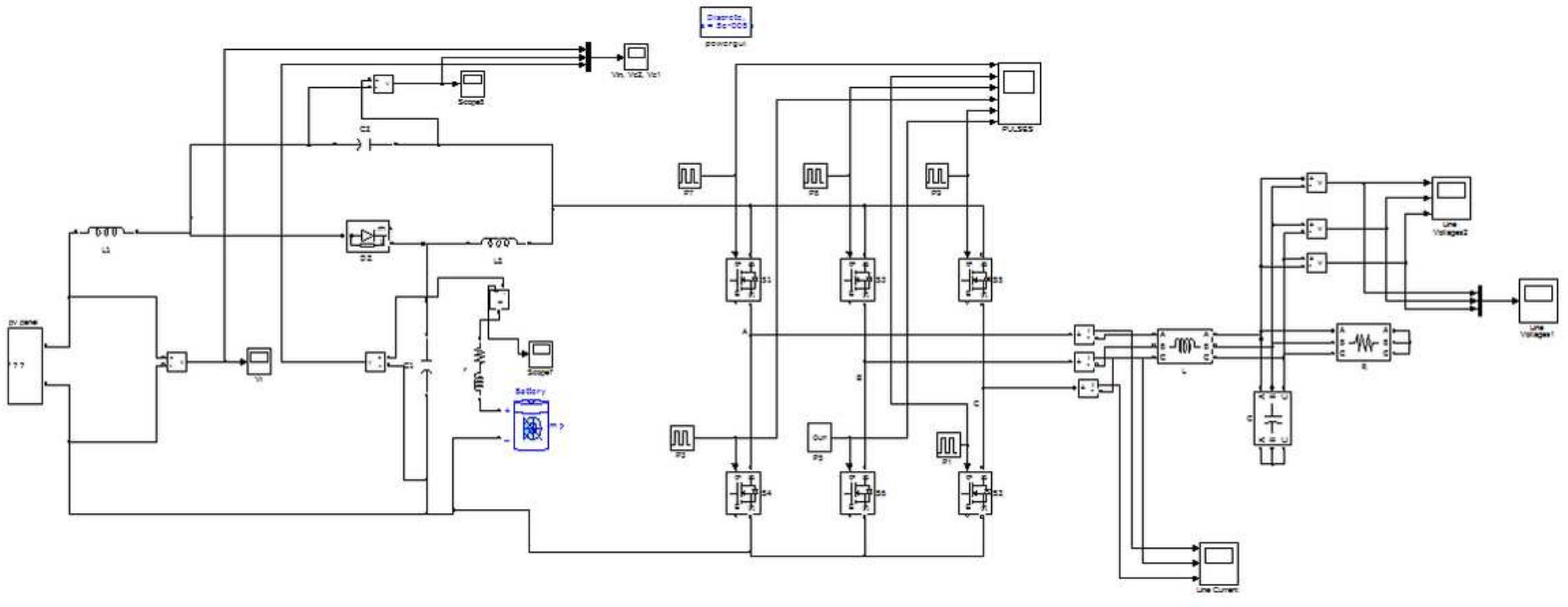

Figure 4

Simulink model of the reported work with $\mathrm{R}$ load 


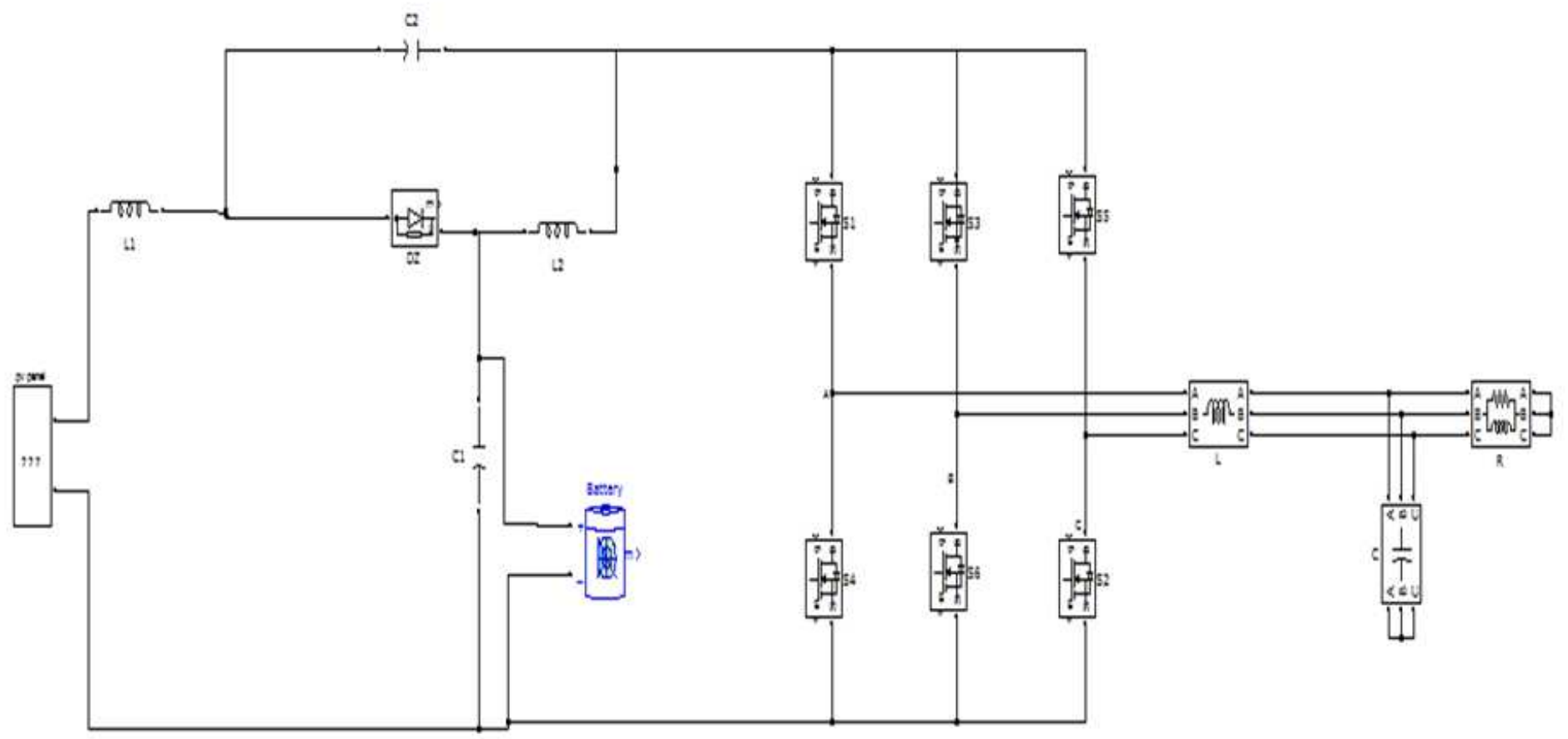

Figure 5

Simulink model of the reported work with RL load

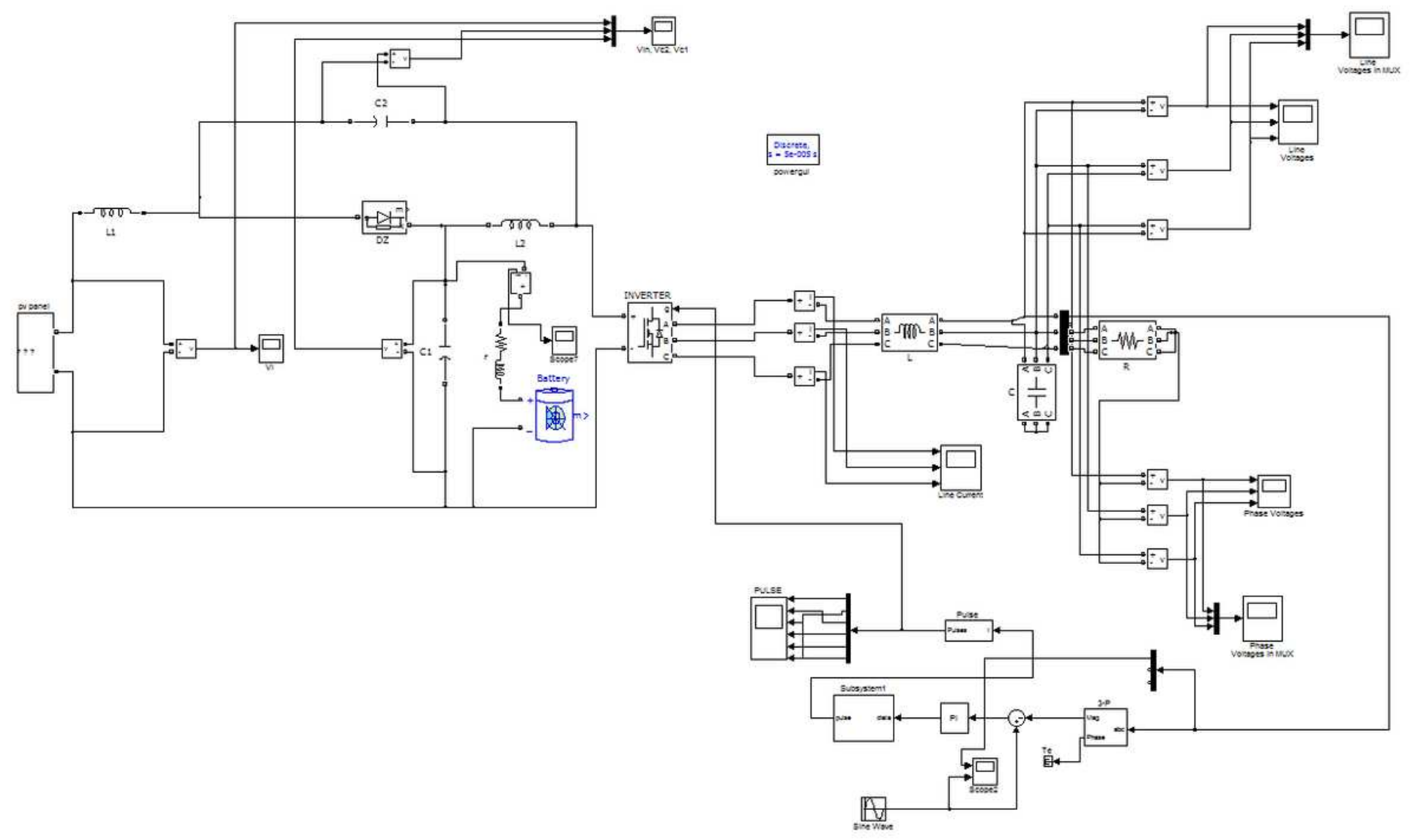


Figure 6

Simulink model of the proposed work with R load

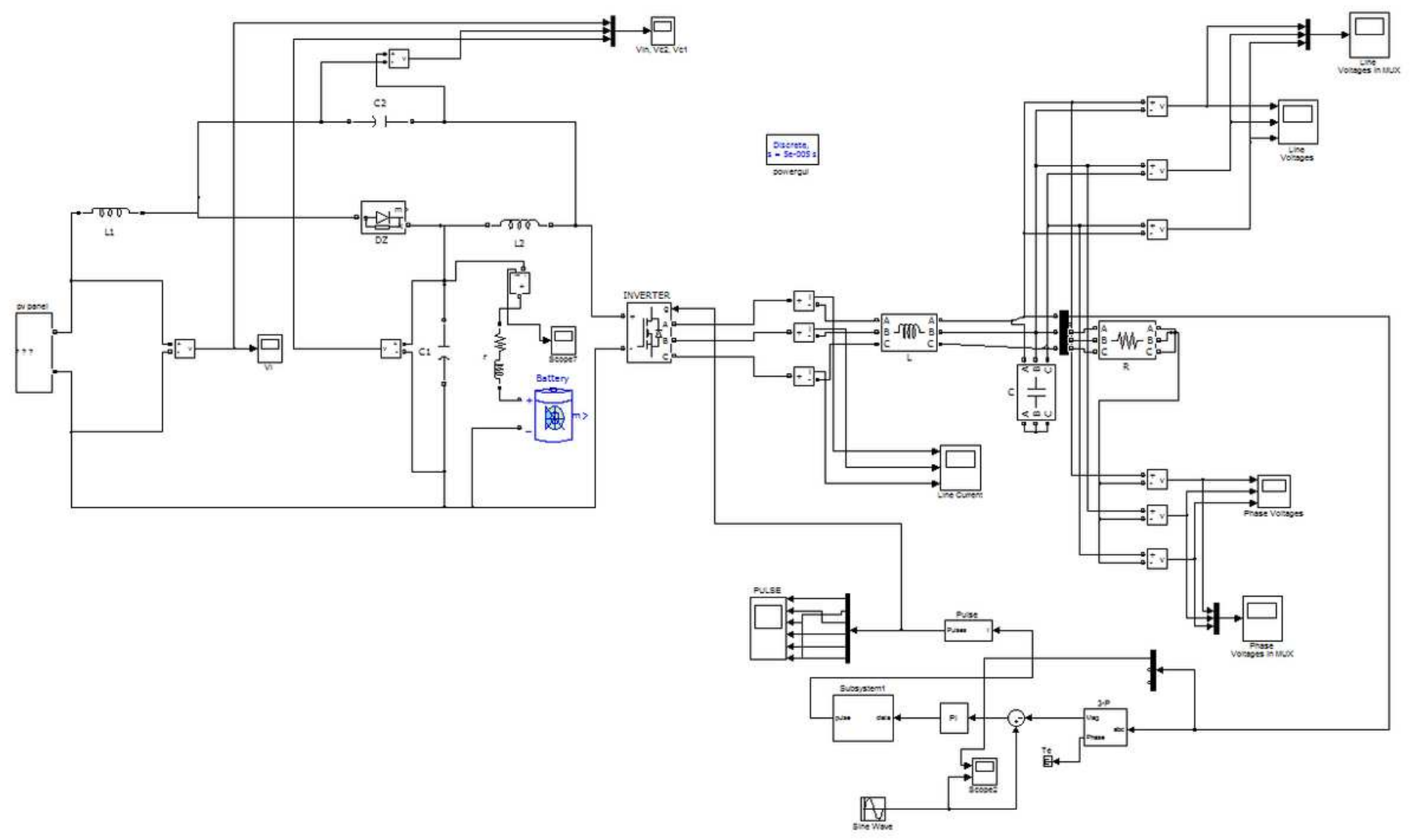

Figure 7

Simulink model of the proposed work with RL load

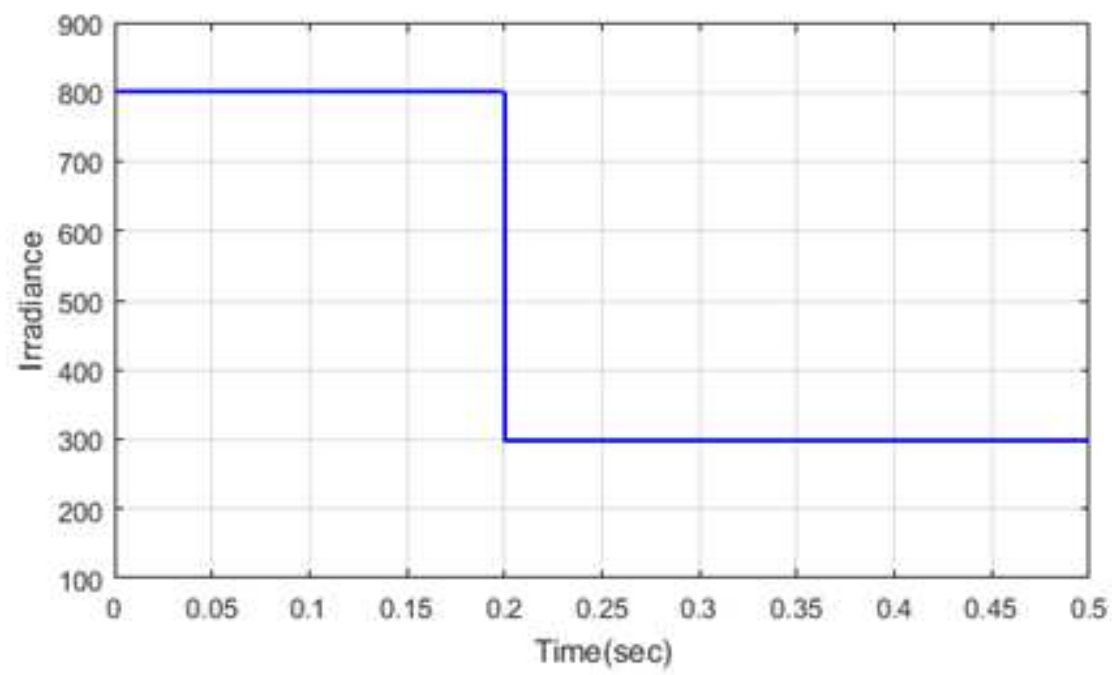

Figure 8 
Analysis of input irradiance for proposed method in R load

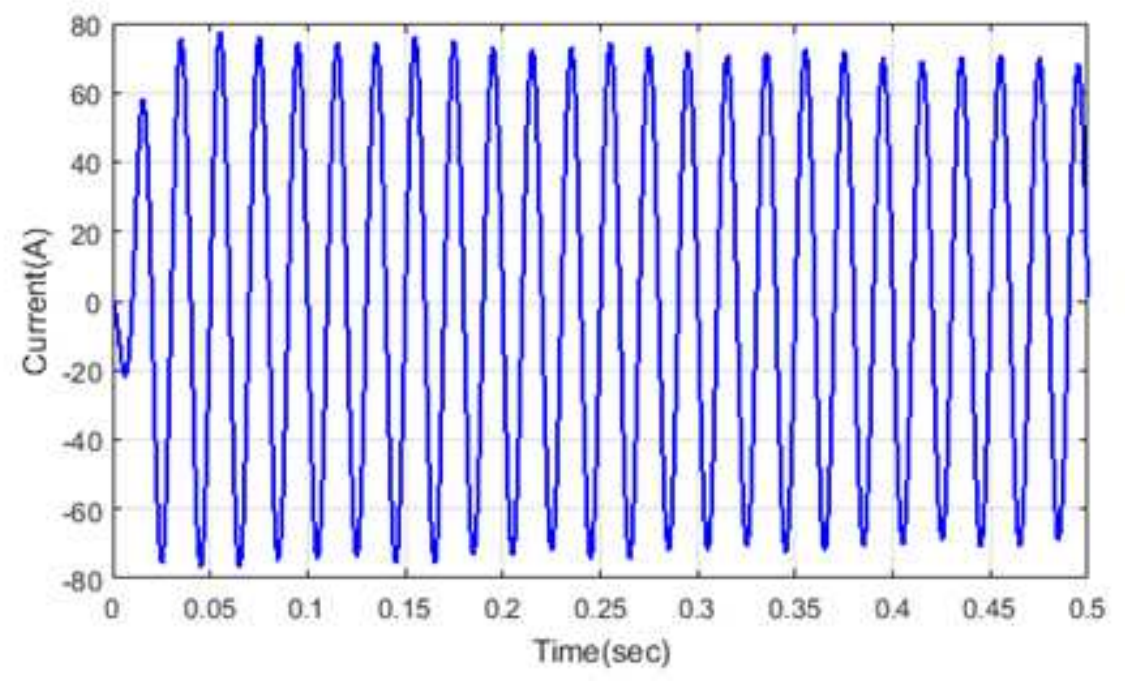

(a)

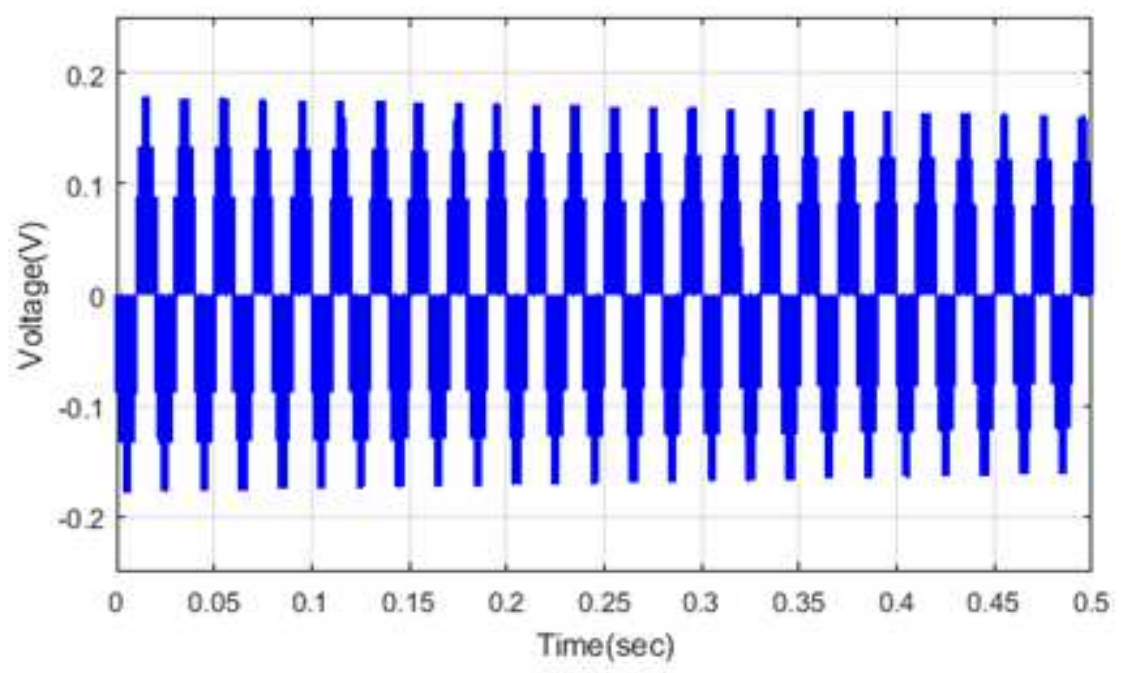

(b)

Figure 9

Analysis of (a) modulation current and (b) inverter voltage for proposed method 


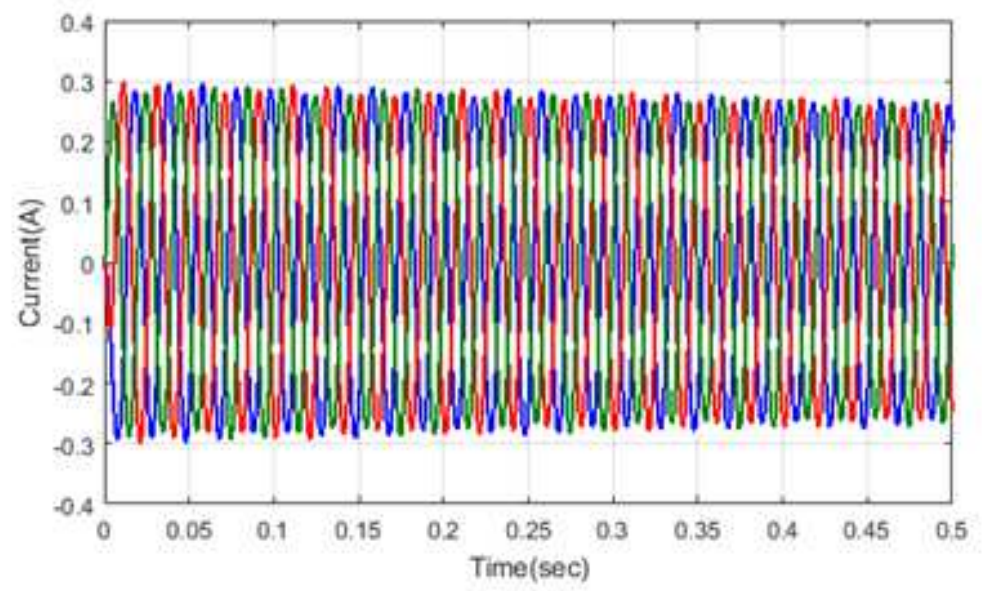

(a)

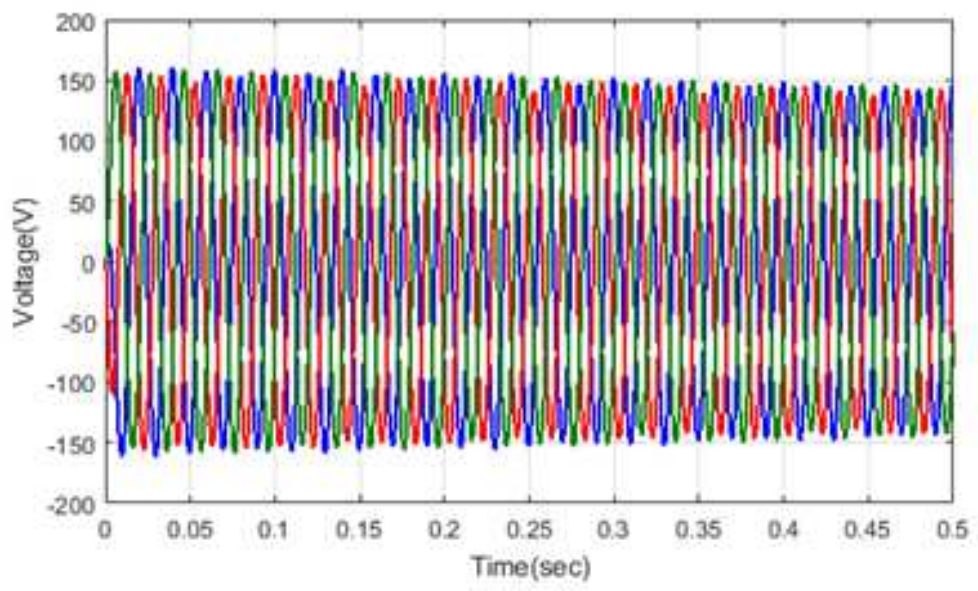

(b)

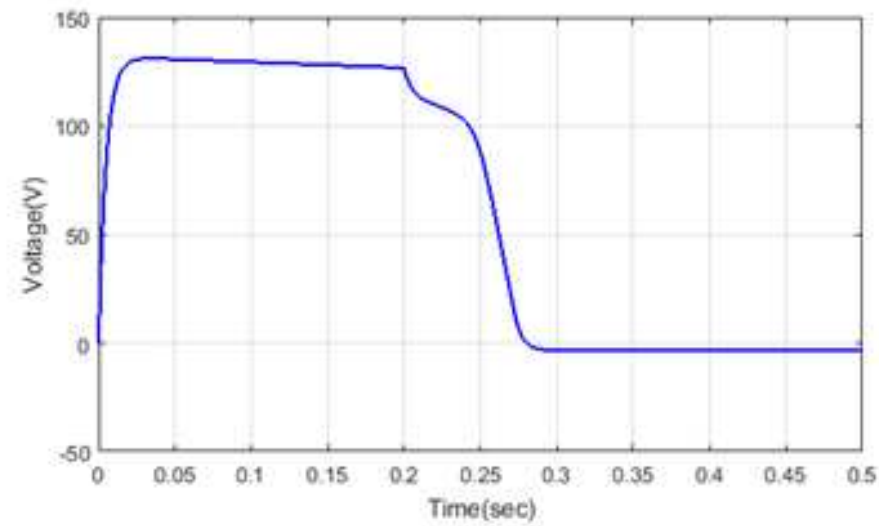

(c)

Figure 10

Analysis of (a) load current (b) load voltage and (c) dc link voltage for proposed method 


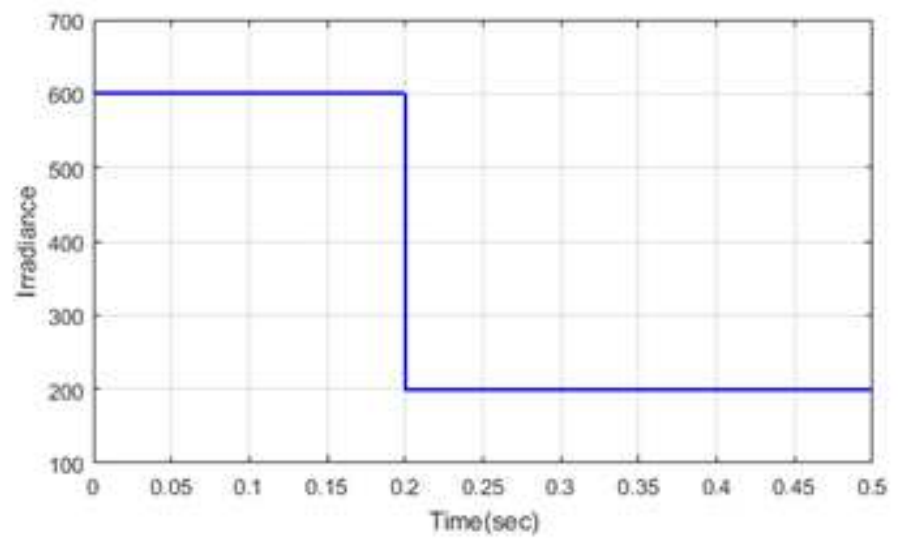

Figure 11

Analysis of irradiance for proposed method in RL load 


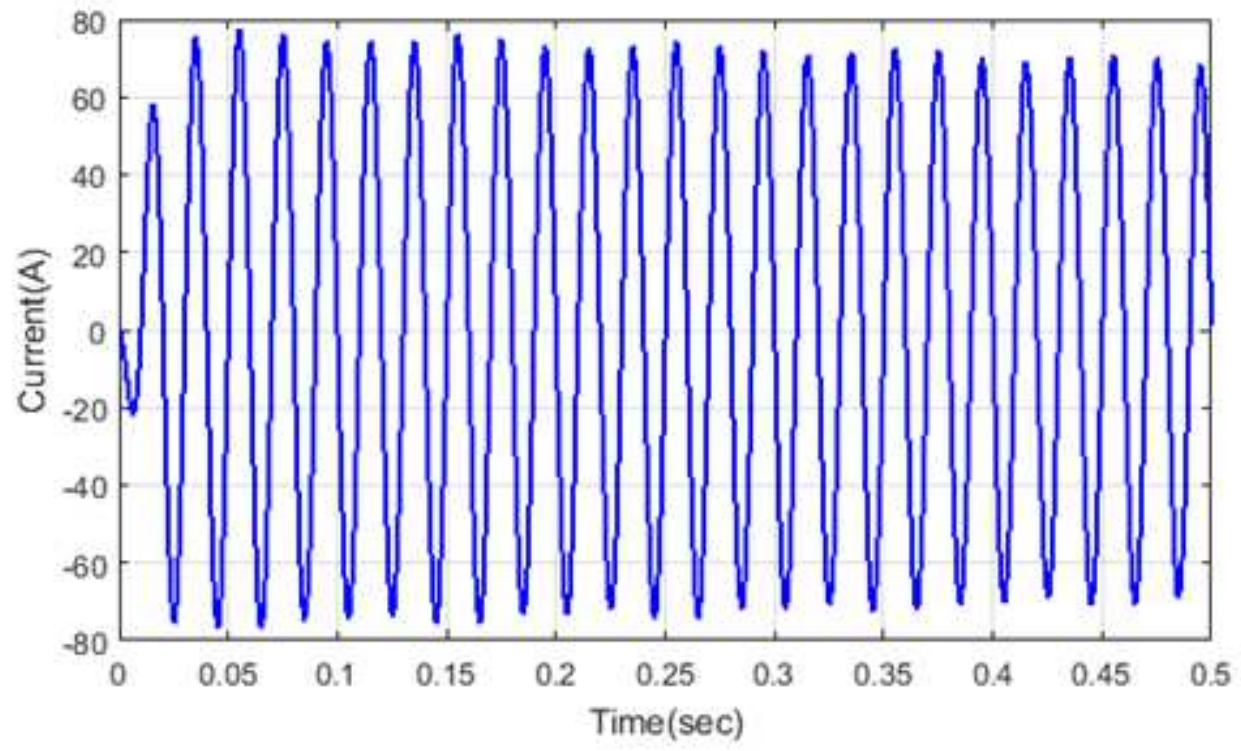

(a)

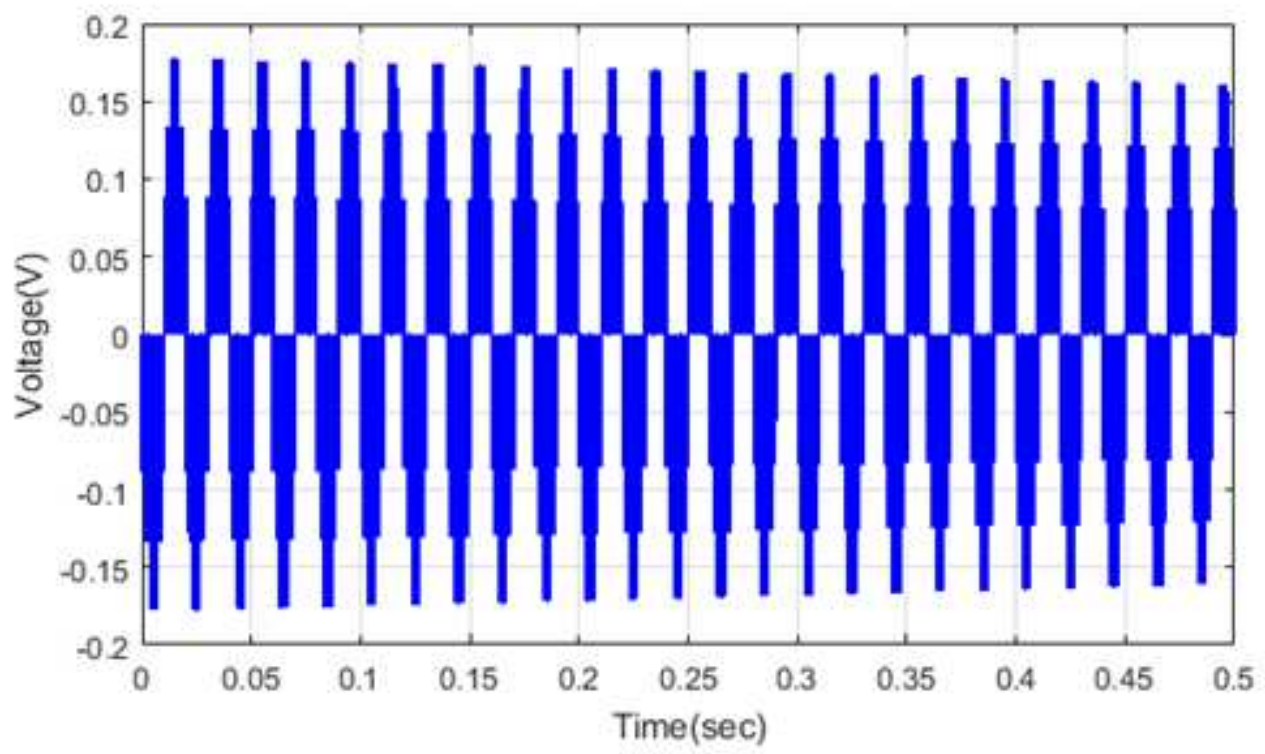

(b)

Figure 12

Analysis of (a) current and (b) inverter voltage for proposed method 


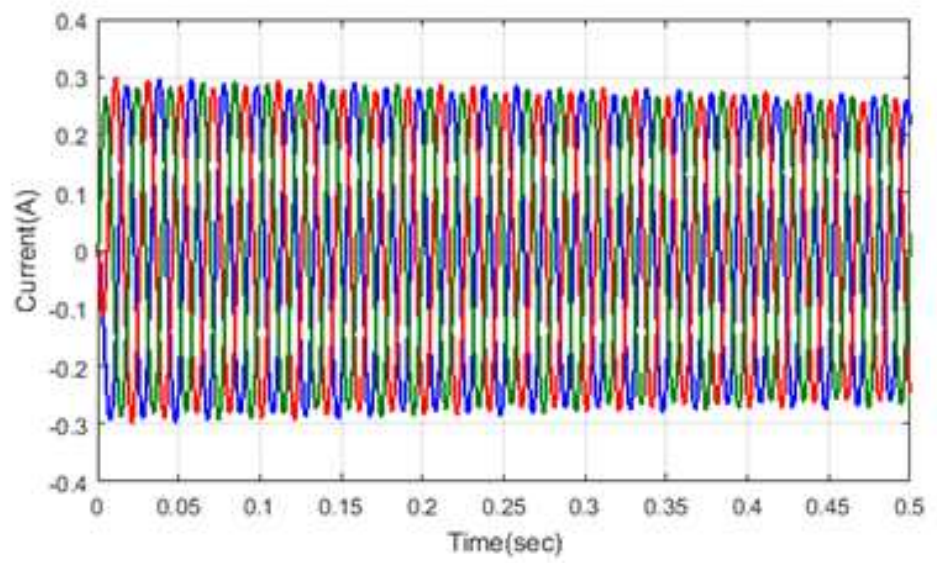

(a)

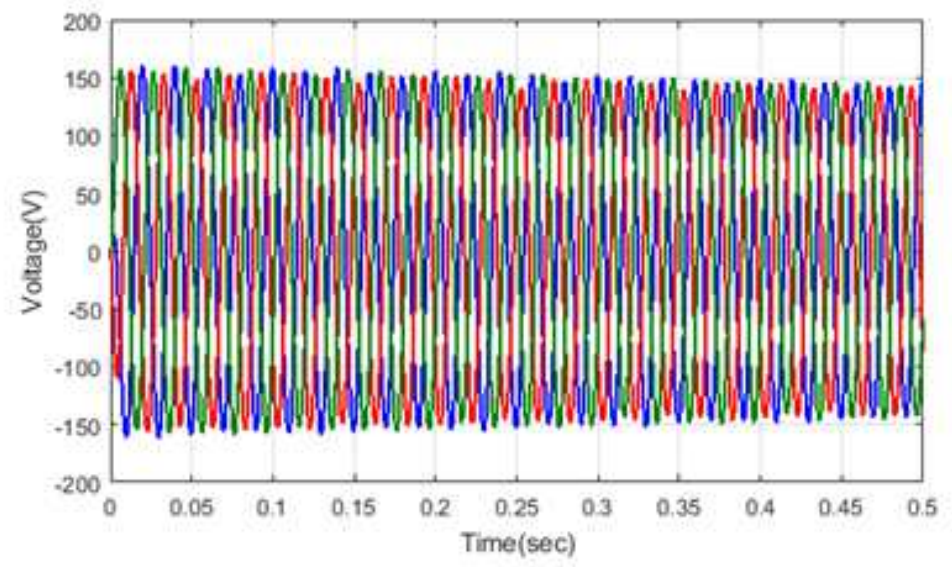

(b)

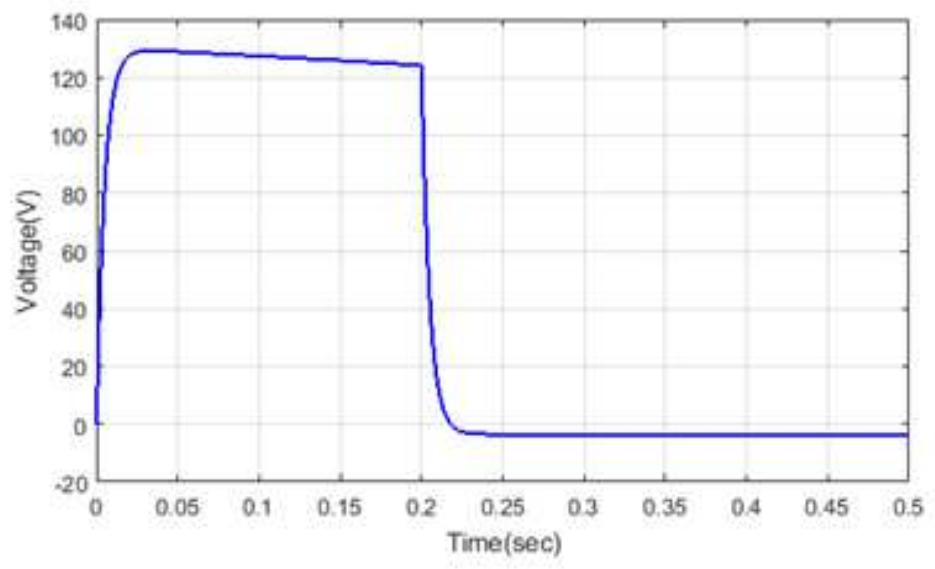

(c)

Figure 13

Analysis of (a) load current (b) load voltage and (c) dc link voltage for proposed method 


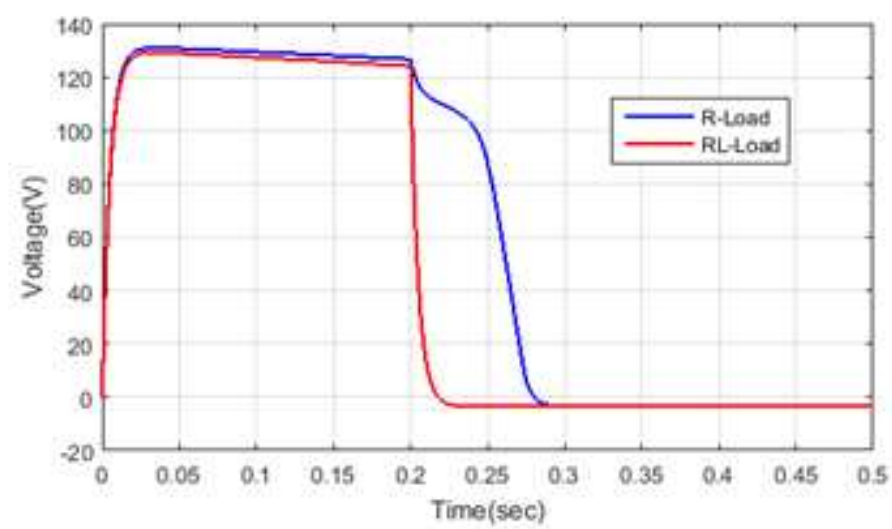

Figure 14

Comparison analysis of R load and RL load for proposed method

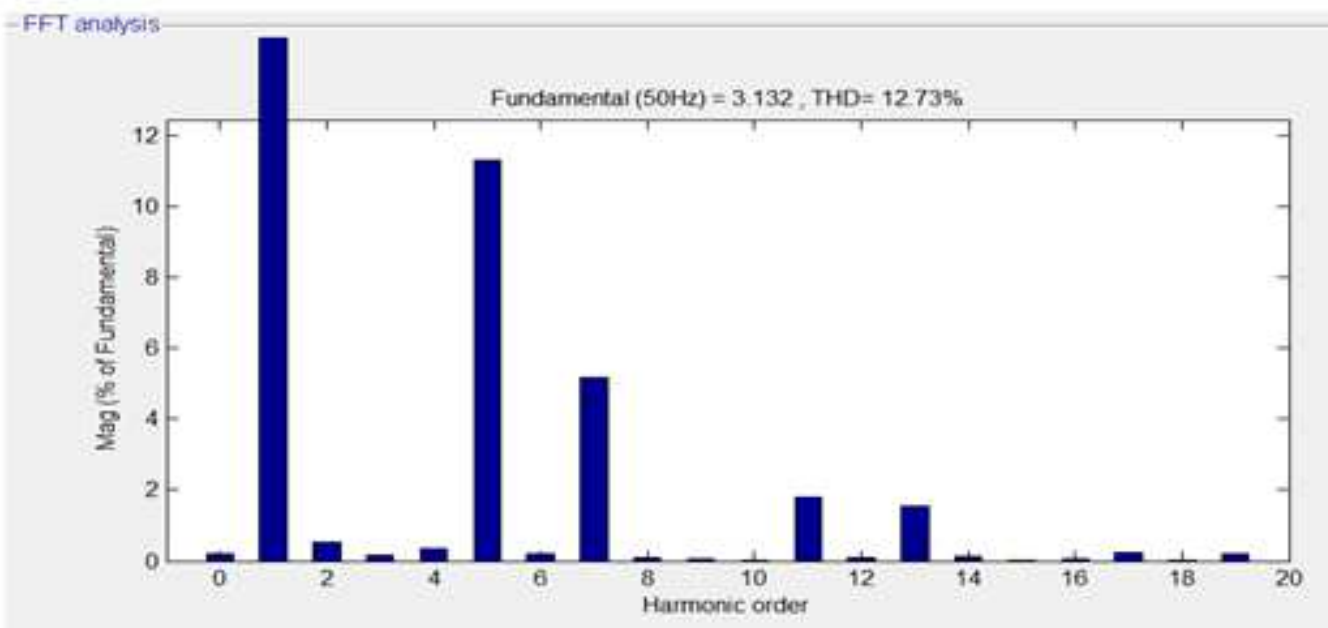

Figure 15

THD in Line current of the reported system using R load

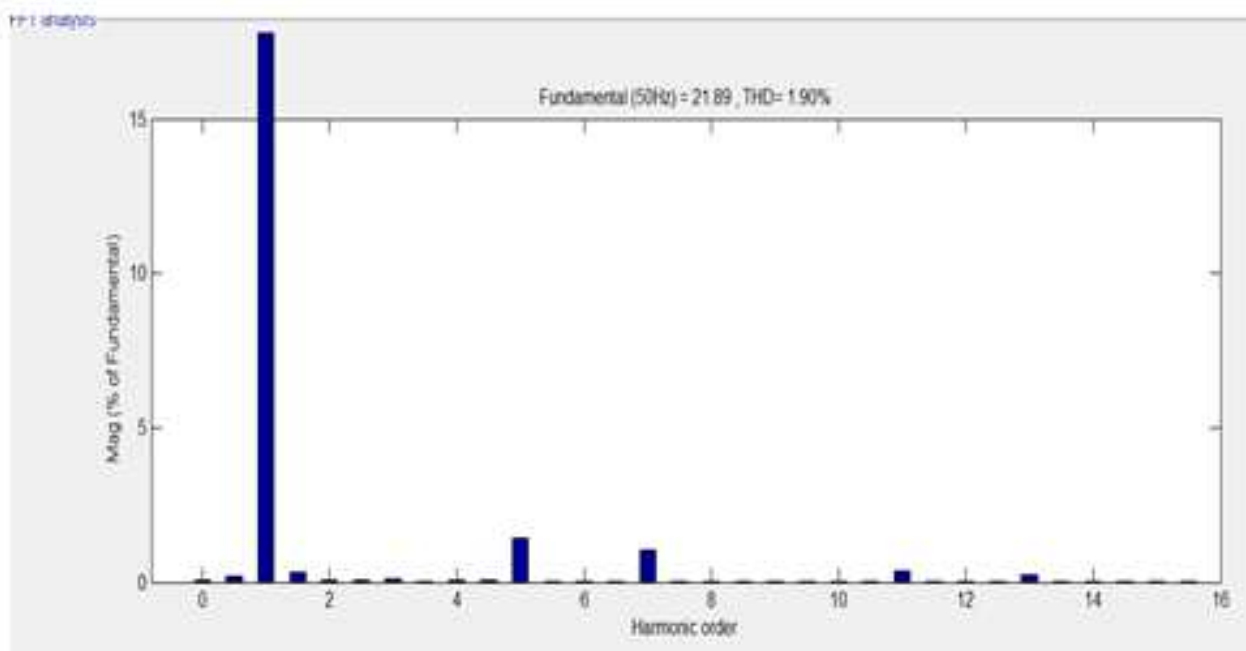


Figure 16

THD in Line current of the proposed work with $\mathrm{R}$ load

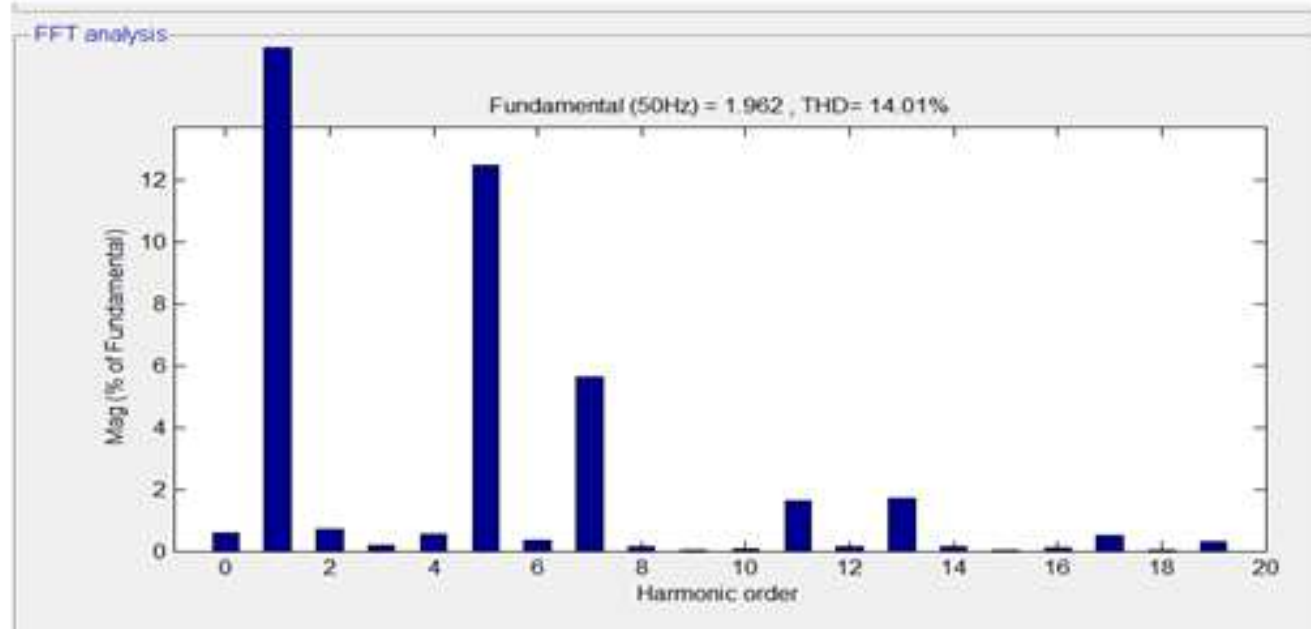

Figure 17

THD in Line current of the reported system using RL load

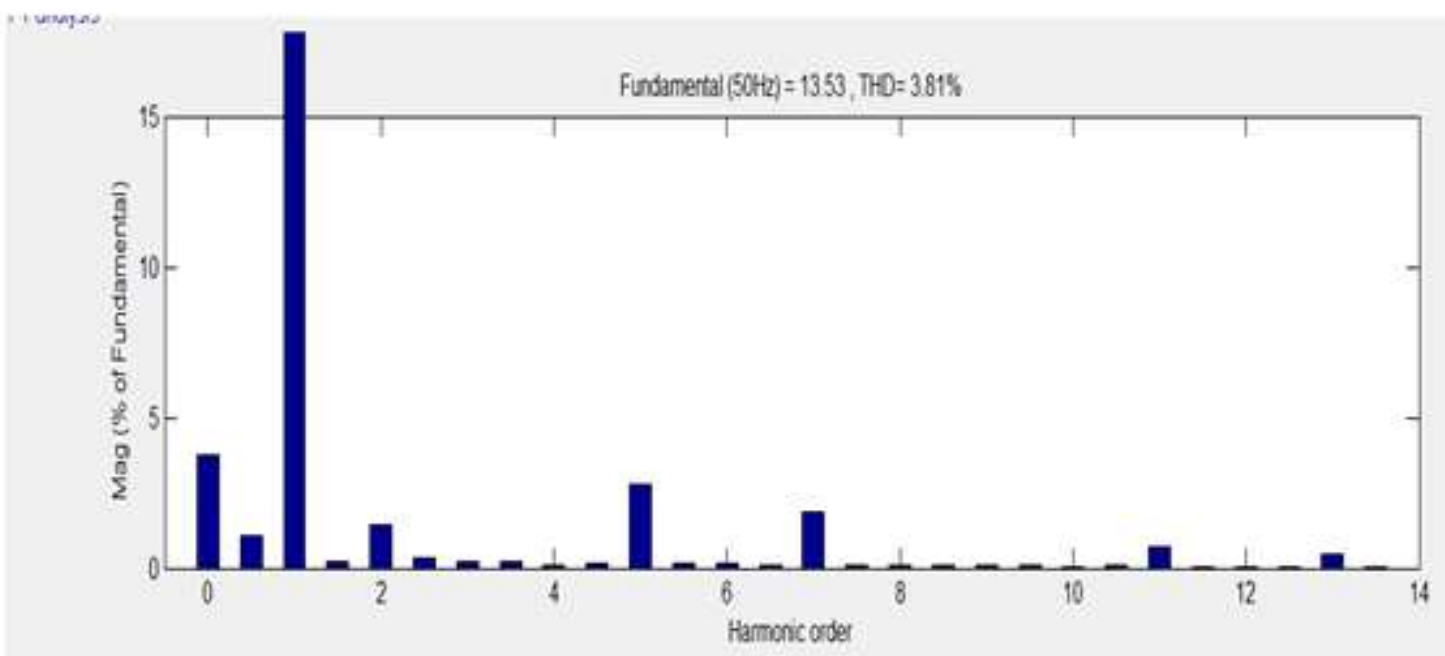

Figure 18

THD in Line current of the proposed work with RL load 